Groundwater Resources Program

\title{
CRT_Cascade Routing Tool to Define and Visualize Flow Paths for Grid-Based Watershed Models
}

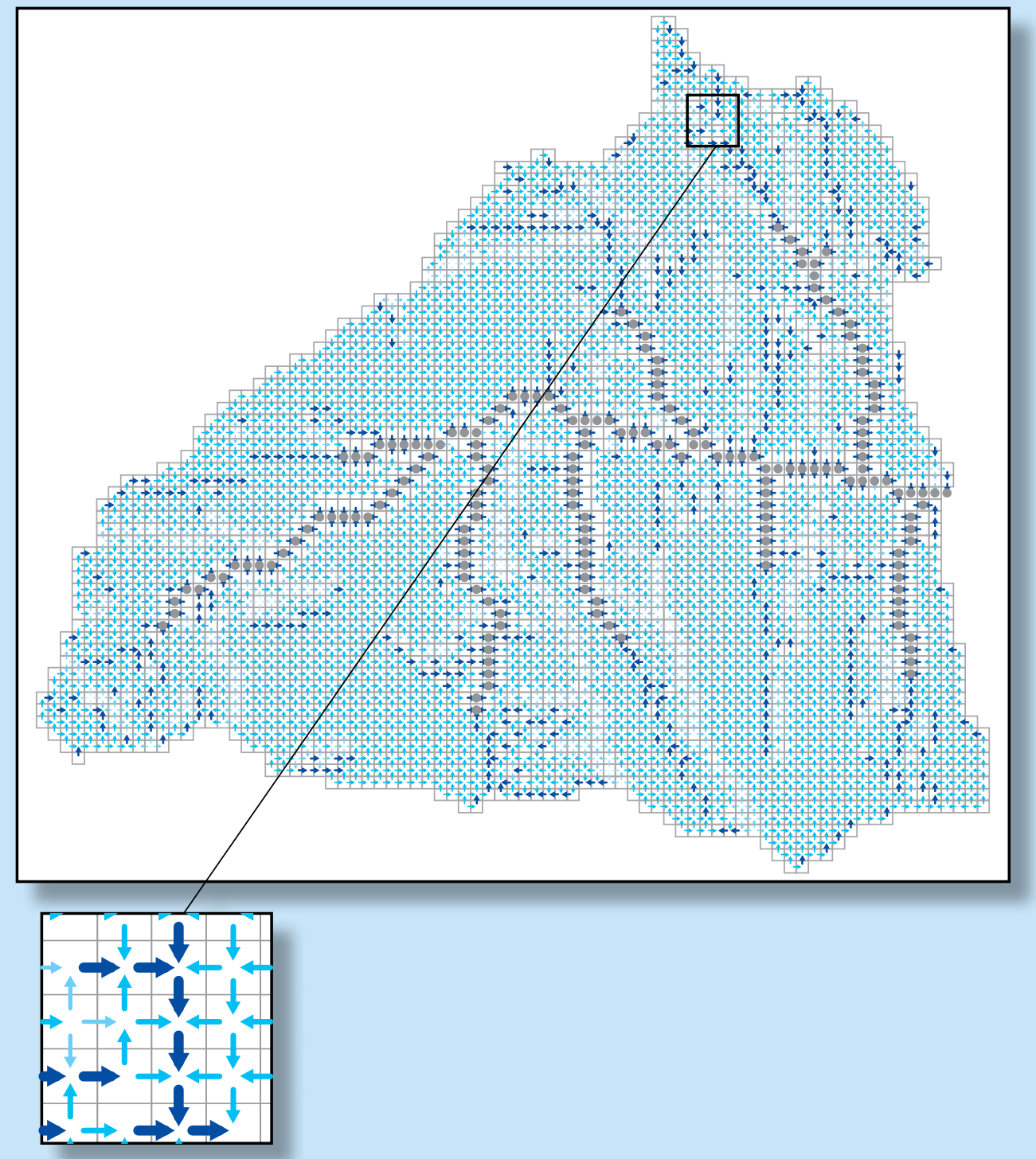

Techniques and Methods 6-D2 



\section{CRT-Cascade Routing Tool to Define and Visualize Flow Paths for Grid-Based Watershed Models}

By Wesley R. Henson, Rose L. Medina, C. Justin Mayers, Richard G. Niswonger, and R.S. Regan

Groundwater Resources Program

Techniques and Methods 6-D2 


\section{U.S. Department of the Interior \\ KEN SALAZAR, Secretary}

\section{U.S. Geological Survey \\ Suzette M. Kimball, Acting Director}

U.S. Geological Survey, Reston, Virginia: 2013

For more information on the USGS - the Federal source for science about the Earth, its natural and living resources, natural hazards, and the environment, visit http://www.usgs.gov or call 1-888-ASK-USGS.

For an overview of USGS information products, including maps, imagery, and publications, visit http://www.usgs.gov/pubprod

To order this and other USGS information products, visit http://store.usgs.gov

Any use of trade, firm, or product names is for descriptive purposes only and does not imply endorsement by the U.S. Government.

Although this information product, for the most part, is in the public domain, it also may contain copyrighted materials as noted in the text. Permission to reproduce copyrighted items must be secured from the copyright owner.

Suggested citation:

Henson, W.R., Medina, R.L., Mayers, C.J., Niswonger, R.G., and Regan, R.S., 2013, CRT—Cascade Routing Tool to define and visualize flow paths for grid-based watershed models: U.S. Geological Survey Techniques and Methods 6-D2, 28 p. 


\section{Preface}

This report describes a new computer program - the Cascade Routing Tool (CRT) - to define surface and subsurface flow paths within grid-based watershed models. CRT was designed specifically for use with the U.S. Geological Survey Precipitation-Runoff Modeling System (PRMS) watershed model and the GSFLOW coupled groundwater/surface-water flow model. CRT includes an ArcGIS based toolbox - the Cascade Routing Visualization (CRV) - that can be used to visualize cascade flow paths. The performance of the programs has been tested in a variety of applications, some examples are documented in this report. Future applications, however, might reveal errors that were not detected in the test simulations. Users are requested to notify the U.S. Geological Survey of any errors found in this report or the computer programs by using the address on the inside of the back cover of the report. Updates might occasionally be made to both the report and to the computer programs. Users can check for updates on the Internet at http://water.usgs.gov/software/lists/groundwater/. 


\section{Contents}

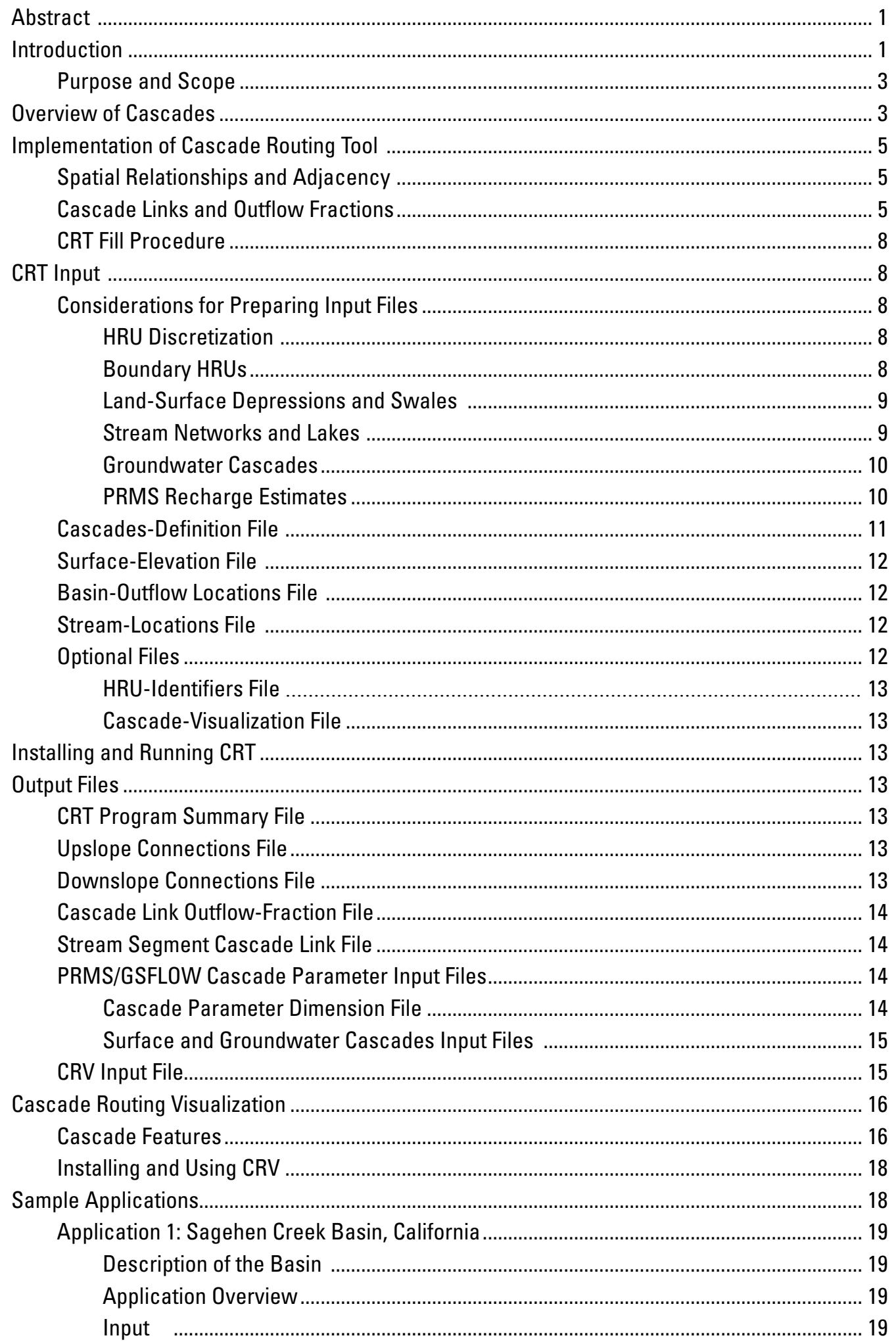


Input for Application 1A: All Streams With Fill Procedure........................................ 21

Input for Application 1B: PRMS-Only Groundwater Cascades by Using SteadyState Potentiometric Surface ............................................................................ 21

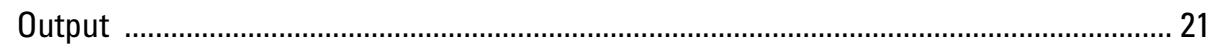

Application 2: Lower Walker River Basin, Nevada ............................................................. 24



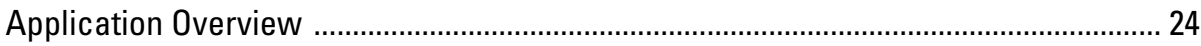

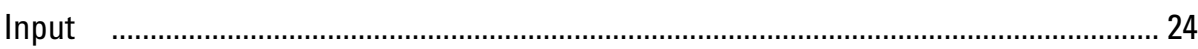

Input for application 2A: Cascades Generated Without Stream Reaches................ 24

Input for Application 2B: Cascades Generated With Selected Stream Reaches .... 26

Input for Application 2C: PRMS-Only Groundwater Cascades Using Topography.. 26

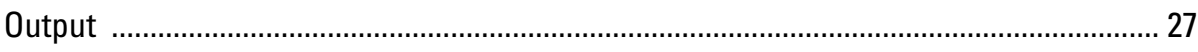

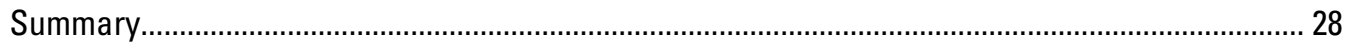



\section{Figures}

1. Diagram showing cascading flow patterns of overland flow among hydrologic response units and streams delineated from $A$, topography intersected by elevation bands and from $B$, a rectangular grid

2. Diagram showing hypothetical model grid with four rows and four columns showing $A$, types of cascading hydrologic response units and $B$, land-surface altitudes and cascading flow directions

3. Diagram showing hypothetical model grid with four rows and four columns illustrating different types of conditions in which multiple streams reaches can be located within a single hydrologic response unit (HRU): in $A$, cascading flow distributed equally to the three connected reaches in HRU 14 and in $B$, cascading flow distributed equally to the two parallel reaches in HRU 10

4. Diagram showing hypothetical model grid with four rows and four columns showing $A$, a case in which hydrologic response unit identifications and grid cell identifications are equivalent and $B$, a case in which HRU_IDS and CELL_IDS are numbered differently

5. Excerpt from the Lower Walker River Basin sample application 2A HRU_CASC.DAT file showing definition of lake hydrologic response units by using HRU TYPE $=2$....... 10

6. Diagram showing Cascade Routing Visualization generated hypothetical cascade links and cascade types

7. Diagram showing the cartographic representations applied by Cascade Routing Visualization to hypothetical cascade link line features and the cascade types

8. Map showing Sagehen Creek Basin PRMS model domain showing active model boundary; stream network; and springs

9. Line 1 from HRU_CASC.DAT input file for Sagehen Creek Basin application .................21

10. Lines 1-6 of the STREAM_CELLS.DAT input file for Sagehen Creek Basin application

11. Excerpt from outputstat.txt showing a summary of Cascade Routing Tool options and filled hydrologic response units for the Sagehen Creek Basin application 
12. Diagram showing $A$, Depiction of Sagehen Creek Basin PRMS model domain showing stream network, cascade flow arrows, and undeclared swales. $B$, Part of the model domain showing undeclared swales and cascade flow arrows before the landsurface model was corrected with Cascade Routing Tool (CRT) Fill Procedure. $C$, The same part of the model domain after elimination of the undeclared swales by use of the CRT Fill Procedure

13. Map showing Lower Walker River PRMS/GSFLOW model domain showing active model boundary; stream network; and non-stream cascade-discharge features Walker Lake, Webber Reservoir, and Double Springs Playa, Nevada

14. Line 1 of HRU_CASC.DAT input file for the Lower Walker River Basin application $2 A$ showing use of option STRMFLG $=0$

15. Line 1 of the HRU_CASC.DAT input file for the Lower Walker River Basin application $2 \mathrm{C}$ showing use of option STRMFLG $=1$

16. Lines 1-2 and 284-288 of the STREAM_CELLS.DAT input file for the Lower Walker River Basin application 2C showing use of option ON_OFF $=0$ 26

17. Diagram showing depiction of Lower Walker River Basin PRMS and GSFLOW model domains showing stream network, lake boundaries, Double Springs Playa designated swale, cascade flow arrows, and undeclared swales: $A$, model domain with no stream reaches, $B$, model domain with selected stream reaches, $C$, part of the model domain showing cascade flow arrows in the simulation with no stream reaches, and $D$, part of the model domain showing cascade flow arrows in the simulation with selected streams

\section{Tables}

1. Selected input parameters for the GSFLOW Cascade Module 5

2. Cascade-link parameters for the hypothetical model shown on figure 2 demonstrating FLOWFLG $=0$ and FLOWFLG $=1$ approaches for allocating flows to downslope hydrologic response units

3. Comparison of CRT output parameters CASCADE TYPE_UP and CASCADE TYPE_DOWN and CRV output feature class attribute CĀSCADE_TYPE 


\section{Conversion Factors and Datums}

Inch/Pound to SI

\begin{tabular}{|c|c|c|}
\hline Multiply & By & To obtain \\
\hline \multicolumn{3}{|c|}{ Length } \\
\hline foot (ft) & 0.3048 & meter $(\mathrm{m})$ \\
\hline mile (mi) & 1.609 & kilometer $(\mathrm{km})$ \\
\hline \multicolumn{3}{|l|}{ SI to Inch/Pound } \\
\hline Multiply & By & To obtain \\
\hline \multicolumn{3}{|c|}{ Length } \\
\hline meter $(\mathrm{m})$ & 3.281 & foot $(\mathrm{ft})$ \\
\hline kilometer $(\mathrm{km})$ & 0.6214 & mile (mi) \\
\hline
\end{tabular}

Vertical coordinate information is referenced to the North American Vertical Datum of 1988 (NAVD 88).

Horizontal coordinate information is referenced to the North American Datum of 1983 (NAD 83).

Altitude, as used in this report, refers to distance above the vertical datum. 


\title{
CRT—Cascade Routing Tool to Define and Visualize Flow Paths for Grid-Based Watershed Models
}

\author{
By Wesley R. Henson, Rose L. Medina, C. Justin Mayers, Richard G. Niswonger, and R.S. Regan
}

\section{Abstract}

The U.S. Geological Survey Cascade Routing Tool (CRT) is a computer application for watershed models that include the coupled Groundwater and Surface-water FLOW model, GSFLOW, and the Precipitation-Runoff Modeling System (PRMS). CRT generates output to define cascading surface and shallow subsurface flow paths for grid-based model domains. CRT requires a land-surface elevation for each hydrologic response unit (HRU) of the model grid; these elevations can be derived from a Digital Elevation Model raster data set of the area containing the model domain. Additionally, a list is required of the HRUs containing streams, swales, lakes, and other cascade termination features along with indices that uniquely define these features. Cascade flow paths are determined from the altitudes of each HRU. Cascade paths can cross any of the four faces of an HRU to a stream or to a lake within or adjacent to an HRU. Cascades can terminate at a stream, lake, or HRU that has been designated as a watershed outflow location.

\section{Introduction}

Large-scale simulations of surface and shallow subsurface lateral water flow often use pre-defined routing flow paths to drain a watershed (fig. 1). This approach assumes that lateral hydrologic gradients are equal to land-surface gradients and that the flow paths represent the effects of gravity on the flow of water throughout the watershed. The Cascade Routing Tool (CRT) is a computer program that has been developed to compute flow paths among Hydrologic Response Units (HRUs) and Groundwater Reservoirs (GWRs) defined for watersheds simulated by the U.S. Geological Survey (USGS) Precipitation-Runoff Modeling System (PRMS; Leavesly and others, 1983). CRT also can be used to compute flow paths among HRUs for simulations that use the USGS integrated Groundwater and Surface water FLOW model, GSFLOW (Markstrom and others, 2008). GSFLOW couples PRMS with the USGS MODFLOW groundwater model (Harbaugh, 2005).

CRT calculates cascade parameters required by PRMS and GSFLOW when the Cascade Module of these models has been activated. PRMS and GSFLOW can be run without using the Cascade Module; however, for this case, all lateral flows are routed directly to a stream or other hydrologic outflow points in the watershed without considering specific flow paths within the watershed. Use of the cascade module can allow for a more realistic representation of the effects of topography and topology on watershed drainage relative to a simulation without cascades. Cascades are important for simulating divergent and convergent flows that can result in reinfiltration of overland runoff and saturated excess runoff. CRT is used external to the watershed model so that the computed cascades can be evaluated prior to a simulation to make sure that water is routed appropriately.

The full functionality of CRT Version 1.0, which is described in this report, is limited to simulations that use square grid cells to discretize a watershed into HRUs and GWRs. Some features of CRT version 1.0 can be used in models discretized into a grid of rectangular HRUs; see the section titled "HRU Discretization" for more information on HRU discretization. Irregular and polygon HRUs and GWRs can be used with PRMS or GSFLOW, but this version of CRT does not generate cascades for these types of discretizations. Pan and others (2012) classify cascade algorithms according to three types: single-flow direction, bi-flow direction, and multiple-flow directions. CRT is a type of multiple-flow direction algorithm. A maximum of four flow paths can be defined for a single, square or rectangular HRU (or GWR) in CRT; the procedure for defining these paths according to the relative altitude among spatial units has been well established (Ford and Fulkerson, 1956).

Currently (2013), to the authors' knowledge, there is no widely-available software that can be used to develop the required input data for defining cascades in PRMS and GSFLOW; CRT provides this capability. CRT relies on a landsurface elevation model derived from a raster Digital Elevation Model (DEM) that has been resampled to the size of the gridded HRUs used to discretize the watershed, and lists of indices for each stream or lake that intersect HRUs and each HRU where lateral flow exits the watershed or model domain (outflow HRU). CRT reads ASCII input files and produces ASCII output files in a format that can be used directly in PRMS and GSFLOW Parameter and Control Files. CRT has utilities to pre-process elevation data to remove small closed depressions that could interfere with cascade generation. Finally, CRT includes a toolbox, called Cascade Routing Visualization (CRV), for visualizing cascades in ArcGIS. Applications of CRT are presented for two watersheds to demonstrate CRT capabilities for several model configurations and to guide the user through the steps involved in implementing CRT. 
Throughout this document, CRT and CRV input and output parameters are capitalized in bold Courier New font (for example, HRUFLAG), the name of CRT input files are capitalized in bold Times New Roman font (for example, HRU_CASCADE.DAT), CRT output file names are shown in lower-case bold Times New Roman font, (for example, outputstat.txt), and PRMS and GSFLOW Cascade Module parameters and input values are shown in lower-case Courier New font (for example, hru_up_id). In addition, input and output file extensions indicate file type. Cascade parameter files (.param file extension) are generated by CRT for direct input to PRMS and GSFLOW. Data files (.DAT extension) are used for CRT input. Text files (.txt file extension) are files that contain information that can be used to quickly asses the success of a particular CRT execution; this information includes a summary of CRT operation, cascade parameter dimensions,

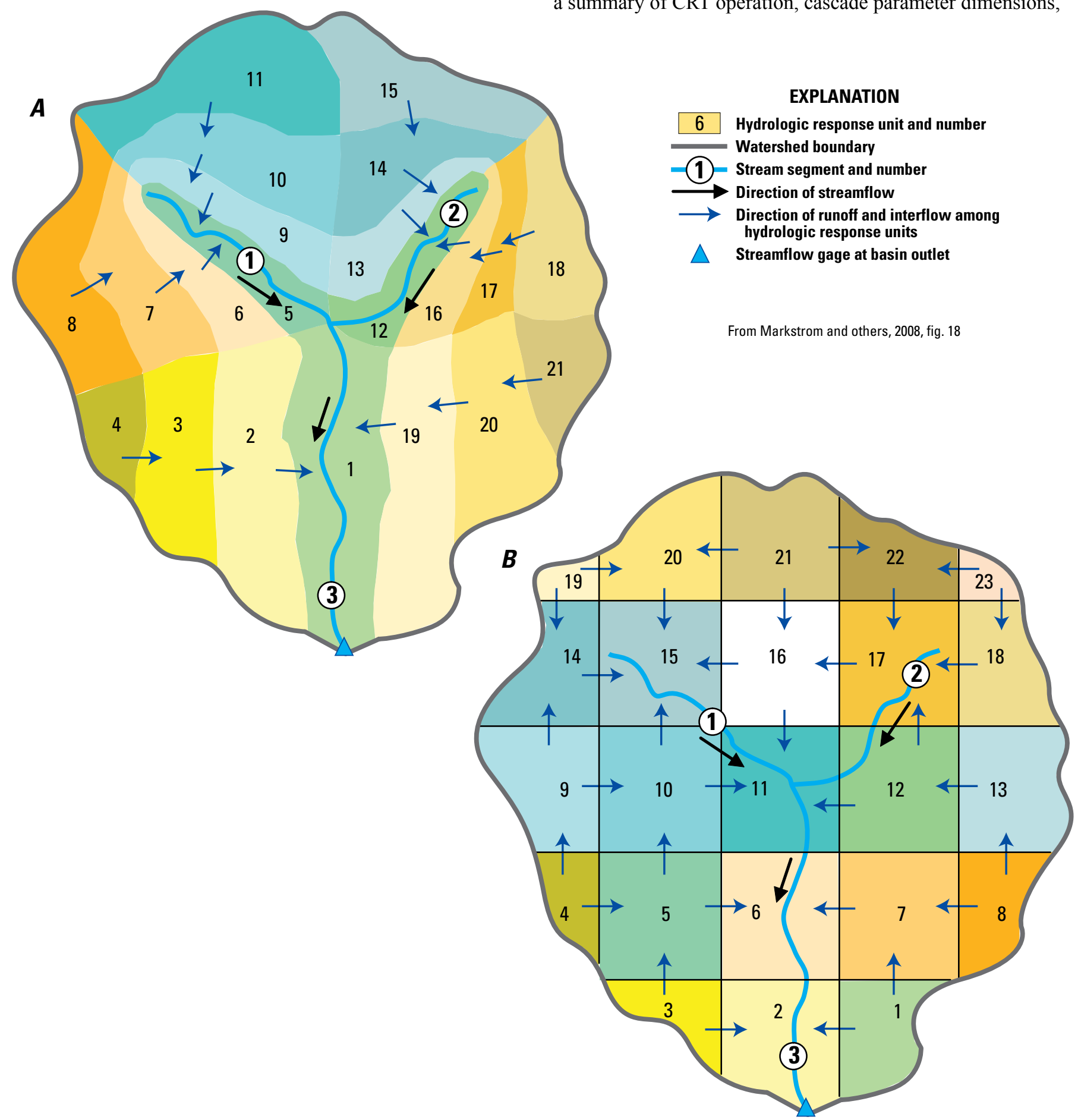

Figure 1. Diagram showing cascading flow patterns of overland flow among hydrologic response units (HRUs) and streams delineated from $\boldsymbol{A}$, topography intersected by elevation bands and from $\boldsymbol{B}$, a rectangular grid. 
and CRV input. Output files (.out file extension) provide the individual cascade parameters computed by CRT. For example, the file hru_up_id.out contains the values for cascade parameter hru_up_id. While the file extensions may vary, all CRT input and output files are written as formatted ASCII data and can be opened with any standard text editing software. PRMS, GSFLOW, CRT, and CRV do not make a distinction between capitalized and lower-case file names and parameters; these formatting conventions serve to distinguish each program's input and output.

\section{Purpose and Scope}

This report describes how CRT can be used to develop required input data for defining cascades for PRMS run in stand-alone mode or for integrated simulations by using GSFLOW. The report provides a description and background of cascades and how they are used to route horizontal flow in a watershed. Two example watersheds are presented to demonstrate the use and capabilities of CRT, including the development of input files, executing CRT, and visualizing CRT output by using the ArcGIS-based Cascade Routing Visualization.

\section{Overview of Cascades}

Cascades are pre-defined flow paths that can be used for routing surface and shallow subsurface lateral flow in hydrologic models. PRMS and GSFLOW include a cascading-flow procedure that relies on a specified flow-direction network (cascades) composed of individual connections (cascade links) between active HRUs and surface-discharge features to route computed flows from upslope HRUs and GWRs to downslope HRUs, GWRs, and cascade-discharge features such as streams, swales, reservoirs, lakes, or outflow HRUs (Markstrom and others, 2008).

The cascading-flow procedure allows flow routing that accounts for changes in hydrologic drainage patterns as water moves from upslope to downslope portions of a basin (figs. 1 and 2). An assumption of the cascade procedure is that flow is routed from (or to) contiguous HRUs, GWRs, lakes, and stream segments. Once flow is routed to a cascade link that terminates in a cascade discharge feature such as a stream or lake, further flow routing is handled by PRMS and GSFLOW; therefore, cascade links among stream segments and among reservoir and lake HRUs are unnecessary.

Cascades are implemented in PRMS and GSFLOW through the Cascade Module. The Cascade Module is active when the values of dimension parameters ncascade and/or ncascdgw are specified to be greater than 0 in the PRMS or GSFLOW Parameter File. The dimension ncascade is the total number of links from HRUs to HRUs, HRUs to stream segments, or HRUs to outflow HRUs in a basin. Likewise, the dimension ncascdgw, is the total number of links for groundwater reservoirs. Cascading-flow computations are made in order from the start of cascade paths to their terminus, such that the outflow from an HRU or a GWR is not computed until all inflows to the reservoir have been calculated.

Cascade parameters define the computation order for routing lateral flows among HRUs and GWRs, and to the routing terminus locations at cascade discharge features. CRT computes the Cascade Module input parameters (including ncascade and ncascdgw). Table 1 defines the cascade parameters required by PRMS and GSFLOW when the cascade procedure is active. Four parameters are used to specify each HRU-to-HRU, and HRU-to-stream segment link, namely hru_up_id, hru_down_id, hru_strmseg_down_id, and hru_pct_up. An HRU-HRU cascade link is defined by setting both $\bar{h} r u \_u p \_i d$ and $h r u \_d o w n \_i d$ to active land-based HRU identifiers. An HRU-to-stream cascade link is defined by setting hru_up_id to an active land-based HRU identifier and hru_strmseg_down_id to a stream segment number; in this case, the value of hru_down_id is ignored. A link between an HRU and lake is defined by setting both hru_up_id to an active land-based HRU identifier and hru_down_id to an active lake HRU identifier (that is, HRU_TYPE $=2$; see Markstrom and others, 2008). The cascade parameterhru_strmseg_down_id must be zero for HRU-to-HRU and HRU-to-lake links and for HRU-to-HRU links where the downslope cascade link contains an outflow HRU. These parameters are of dimension ncascade. For PRMS-only simulations that represent groundwater flow by using PRMS groundwater reservoirs (GWRs), the connectivity pattern of GWR-to-GWR and GWR-to-stream segment is defined by four parameters_-gw_up_id, gw_down_id, gw_strmseg_down_id, and gw_pct_up-each dimensioned by ncascolgw.

CRT is based on the assumption that land-surface cascades provide a good initial approximation of groundwater cascades. This assumption derives from the fact that groundwater-level surfaces often mimic topographic surfaces (Tóth, 1963); therefore, the default procedure used by CRT for computing cascades for GWRs is the same as for HRUs. In PRMS-only simulations, GWR cascades can be the same as or different from HRU cascades; however, groundwater-cascade parameters generated by CRT are equivalent to surface-water cascades. For example, the HRU cascade parameter ncas cade is equal to the GWR cascade parameter ncascdgw, and hru_up_id is equivalent to gw_up_id. Although by default GWR and HRU cascade parameters are computed the same, CRT has the capability to generate GWR cascades that are independent of HRU cascades.

Not all HRUs or stream segments need to be included in the cascade parameter lists. An HRU that is not specified in any cascade link is assumed to be a swale HRU and will have no outflow, which is identical to an outflow HRU cascade. Swales can represent real hydrologic features, such as a wetland or lake that is the same size or smaller than an HRU. The parameter HRU_TYPE can be specified as 3 for all swale HRUs; however, if an HRU is not included in the hru_up_id list, then PRMS will assume it is an undeclared swale HRU, even 
if HRU TYPE is specified as 1. See the section titled "LandSurface Depressions and Swales" for further details regarding swales. Stream segments not included in any HRU or GWR cascade link do not receive lateral inflow from HRUs or GWRs. The GWR connectivity parameters must account for all GWRs; no designated or undeclared swale GWRs can be present. Therefore, if swale or lake HRUs exist, then groundwater cascades should be generated separately from surface cascades; see the section titled "Groundwater Cascades" for guidance on generating GWR cascades.

The parameters hru_pct_up and gw_pct_up assign the decimal fraction of total lateral outflow from an upslope HRU or GWR that is routed by each cascade link. If the sum of hru_pct up or gw pet up decimal fractions for an upslope HRU or GWR is less than 1.0, the Cascade Module apportions the missing decimal fraction evenly among all cascade links originating from that upslope HRU or GWR. Additionally, two scalar parameters are used to simplify cascade links. PRMS and GSFLOW ignore any cascade link with an upslope HRU or GWR area less than the cascade tolerance (cascade_tol; Marsktrom and others, 2008, p. 34) and less than $7 . \overline{5}$ percent of the upslope HRU or GWR area. Cascade links with less than the specified tolerance are ignored, and the associated decimal fraction is evenly apportioned to all other cascade links originating from the HRU or GWR.
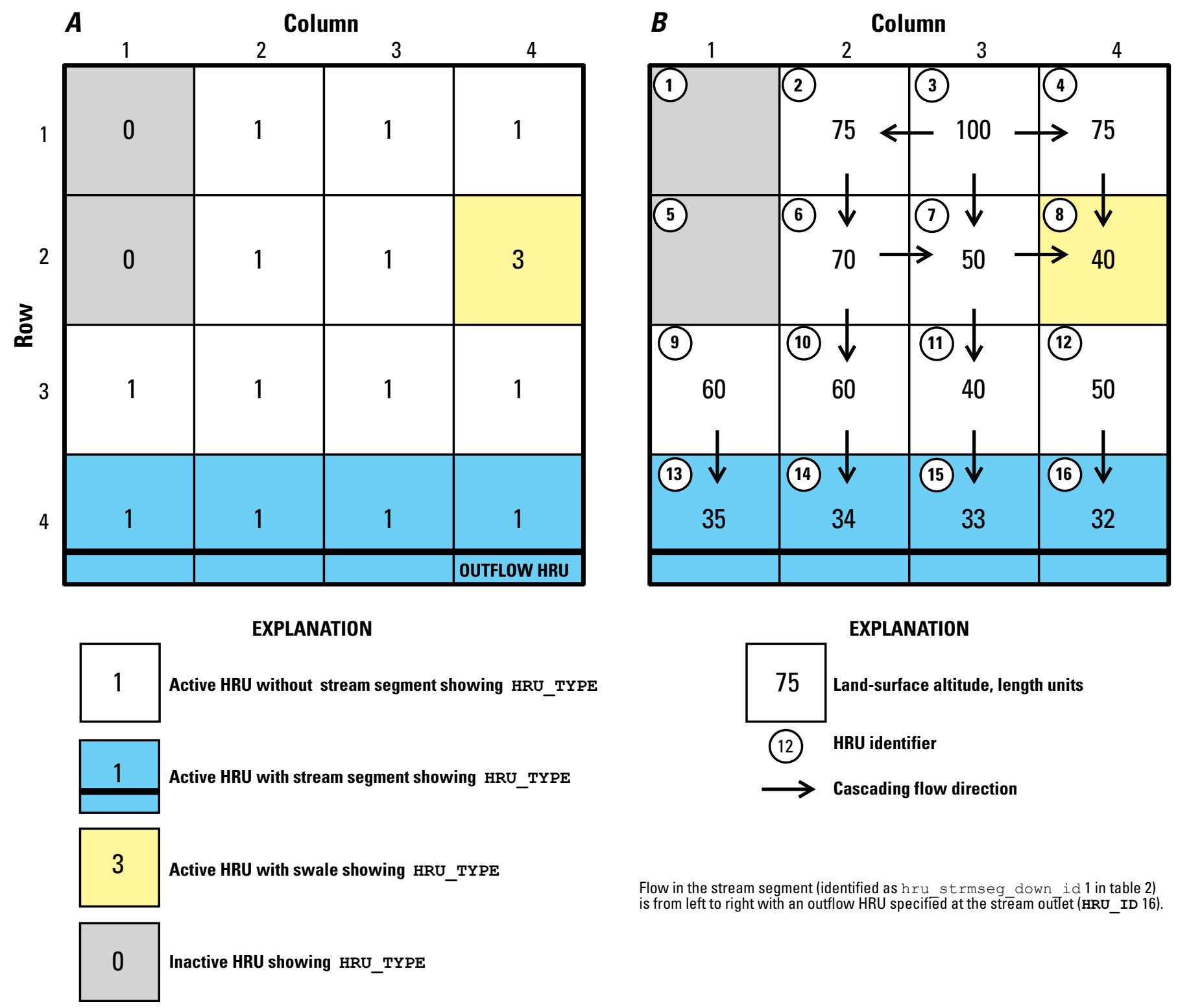

Flow in the stream segment (identified as hru strmseg_down id 1 in table 2) is from left to right with an outflow HRU specified at the stream outlet (HRU_ID 16).

Figure 2. Hypothetical model grid with four rows and four columns showing $\boldsymbol{A}$, types of cascading hydrologic response units (HRUs) and $\boldsymbol{B}$, land-surface altitudes and cascading flow directions. 
Table 1. Selected input parameters for the GSFLOW Cascade Module.

[HRU, hydrologic response unit; GWR, groundwater reservoir; nhru, number of HRUs; ngw, number of groundwater reservoirs; ncascdgw, total number of cascade links among groundwater reservoirs; ncascade, total number of cascade links among HRUs and stream segments; nsegment, number of stream segments]

\begin{tabular}{|c|c|c|c|c|c|}
\hline Parameter name & Description & Dimension variable & Units & Type & Range \\
\hline HRU_TYPE & $\begin{array}{l}\text { Type of each HRU } \\
\quad(0=\text { inactive; } \\
\text { 1=land; } 2=\text { lake; } \\
3=\text { swale })\end{array}$ & nhru & None & Integer & 0 to 3 \\
\hline \multicolumn{6}{|c|}{ Input parameters related to HRUs } \\
\hline hru_up_id & $\begin{array}{l}\text { Identifier of HRU of } \\
\text { upslope link }\end{array}$ & ncascade & None & Integer & 0 to nhru \\
\hline hru_down_id & $\begin{array}{l}\text { Identifier of HRU of } \\
\text { downslope link }\end{array}$ & ncascade & None & Integer & 1 to nhru \\
\hline hru_pct_up & $\begin{array}{l}\text { Fraction of outflow } \\
\text { from upslope link } \\
\text { to downslope link }\end{array}$ & ncascade & decimal fraction & Real & 0.0 to 1.0 \\
\hline gw_up_id & $\begin{array}{l}\text { Identifier of GWR of } \\
\text { upslope link }\end{array}$ & ncascdgw & None & Integer & 1 to $\mathrm{ngw}$ \\
\hline gw_down_id & $\begin{array}{l}\text { Identifier of GWR of } \\
\text { downslope link }\end{array}$ & ncascdgw & None & Integer & 0 to $\mathrm{ngw}$ \\
\hline gw_pct_up & $\begin{array}{l}\text { Fraction of outflow } \\
\text { from upslope link } \\
\text { to downslope link }\end{array}$ & ncascdgw & decimal fraction & Real & 0.0 to 1.0 \\
\hline gw_strmseg_down_id & $\begin{array}{l}\text { Identifier of stream } \\
\text { segment receiving } \\
\text { flow }\end{array}$ & ncascdgw & None & Integer & 0 to $n$ segment \\
\hline
\end{tabular}

\section{Implementation of Cascade Routing Tool}

\section{Spatial Relationships and Adjacency}

Each HRU defined for a PRMS or GSFLOW simulation is assigned an HRU identifier that is used to index HRU parameter data. In CRT, HRU-identifiers (HRU_IDs) can be user-specified or automatically assigned by CRT as the input data are read. During CRT initialization, each grid-based HRU is assigned an identifier (CELL_ID). CELL_IDs are used by CRT to determine adjacent grid-based HRUs. Grid CELL_IDs are assigned similar to the MODFLOW convention, starting in the upper left corner of the grid and increasing sequentially across columns in a single row and continuing again on the left side of a new row, as shown in figure $2 B$. If HRU_IDs are automatically assigned by CRT, CRT will make CEL $\bar{L} \_$ID and HRU_ID equivalent. If HRU_IDs are specified by the user, they must be listed in the HRU-Identifiers File (HRU ID.DAT). During CRT operation, the cascade calculation order is defined and indexed by using cascade-link identifiers (CASCADE_IDs), which order cascades such that outflow to downslope cascade links is not computed until all inflows from upslope HRUs or GWRs have been computed.

\section{Cascade Links and Outflow Fractions}

Each set of connected cascade links (cascades) starts at an HRU that does not receive flow from an upslope cascade link. Each cascade traverses downslope and must terminate in a stream segment, a lake or swale HRU, or an HRU that contains a predefined watershed outflow HRU. The Cascade Module checks for circular flow paths, which are flow paths in which the calculated flow leaving an HRU is routed back to itself. Circular flow paths can lead to mass-balance errors. Circular flow paths in cascade links must be corrected before PRMS or GSFLOW can be executed with the Cascade Module active. If necessary, CRT Fill Procedure can be used to correct circular flow paths.

Links are established between an HRU and its four neighboring HRUs by simply identifying which of the (active) neighboring HRUs have lower elevations. For example, in figure $2 B$, there are three HRUs adjacent to HRU_ID 3 that have lower elevations than HRU_ID 3; therefore, there are three outflow cascade links associated with the HRU. 
In addition to requiring user-specified cascade links among HRUs, PRMS and GSFLOW simulations also require specification of the percentages of flow from each upslope HRU to each of its downslope receiving HRUs. Although several methods can be used to partition outflow to neighboring downslope HRUs, the current version of CRT includes only two approaches for doing this. In the first approach, which is implemented by setting parameter FLOWFLG to 0 in the HRU_CASC.DAT input file, the outflow is distributed equally to each of the outflow HRUs. For example, for HRU_ID 3 in figure $2 B$, the fraction of flow to each of the three receiving downslope HRUs is 0.33 (table 2). Similarly, for the case in which all outflow is to a single HRU, the fraction of flow to the receiving HRU would be 1.0 ; for the case of two outflow HRUs, the fraction to each receiving HRU would be 0.50 ; and for the case of four outflow HRUs, the fraction to each receiving HRU would be 0.25 .

In the second approach (FLOWFLG $=1$ ), the outflow rates are scaled by the relative slopes between the upslope and downslope HRUs according to the equation:

where

$$
\text { Fraction }_{i, j}=\frac{x}{y}
$$

Fraction $_{i, j}$ is the fraction of flow from upslope HRU $i$ to downslope $\mathrm{HRU} j$,

$x$ is the elevation difference between two HRUs along a cascade link, and

$y$ is the sum of the elevation differences between the upslope HRU and all of the downslope receiving HRUs.
As an example of this approach, the slope from HRU ID 3 to HRU_ID 7 in figure $2 B$ is twice as large as the slope from HRU_ID 3 to either HRU_ID 2 or HRU_ID 4, and the resulting outflow fractions to the three HRUs are 0.50 to HRU_ID 7 and 0.25 to both HRU_ID 2 and HRU_ID 4. This approach requires that HRUs be squares (all sides of equal dimension).

In a PRMS or GSFLOW simulation, streams are subdivided into reaches and segments. A stream reach is a section of a stream associated with a particular HRU. A stream segment is a group of reaches that have (1) uniform rates of overland flow and precipitation to them; (2) uniform rates of evapotranspiration from them; (3) uniform or linearly changing hydraulic properties, such as streambed elevation, thickness, and hydraulic conductivity; (4) tributary flows or specified inflow or outflow rates to them; or (5) diversions from them. For example, the stream reaches in HRU_IDs 13, 14, 15, and 16 in figure $2 B$ compose stream segment number 1 . If a cascade link terminates at an HRU that contains a stream reach, then all lateral flow to that HRU is assumed to discharge to the stream reach contained within the HRU. CRT also assumes that if an HRU is adjacent to an HRU that contains a stream, then all of the flow leaving that HRU is directed to the HRU containing the stream (hru_pct_up=1.0). For example, HRU_IDs 9, 10,11 , and 12 in figure $2 B$ are all adjacent to stream segment 1; therefore, all of the outflow from the four HRUs goes to stream segment 1 , even though the land-surface elevations in HRU_ID 11 are lower than those in adjacent HRU_IDs 10 and 12.

Table 2. Cascade-link parameters for the hypothetical model shown on figure 2 demonstrating FLOWFLG=0 and FLOWFLG=1 approaches for allocating flows to downslope (receiving) hydrologic response units.

[HRU, hydrologic response unit; CASCADE_ID, Cascade-link identifier, index of cascade links; hru_up_id, identifier of HRU of upslope link; hru_down_id, indentifier of HRU of downslope link; hru_pct_up, fraction of outflow from upslope link to downslope link; and hru_strmseg_down_id, identifier of stream segment receiving flow]

\begin{tabular}{|c|c|c|c|c|c|}
\hline CASCADE_ID & hru_up_id & hru_down_id & $\begin{array}{l}\text { hru_pct_up } \\
\text { FLOWFLG=0 }\end{array}$ & $\begin{array}{l}\text { hru_pct_up } \\
\text { FLOWFLG=1 }\end{array}$ & $\begin{array}{c}\text { hru_strmseg } \\
\text { down id }\end{array}$ \\
\hline 1 & 2 & 6 & 1.00 & 1.00 & 0 \\
\hline 2 & 3 & 4 & 0.33 & 0.25 & 0 \\
\hline 3 & 3 & 2 & 0.33 & 0.25 & 0 \\
\hline 4 & 3 & 7 & 0.33 & 0.50 & 0 \\
\hline 5 & 4 & 8 & 1.00 & 1.00 & 0 \\
\hline 6 & 6 & 7 & 0.50 & 0.67 & 0 \\
\hline 7 & 6 & 10 & 0.50 & 0.33 & 0 \\
\hline 8 & 7 & 8 & 0.50 & 0.50 & 0 \\
\hline 9 & 7 & 11 & 0.50 & 0.50 & 0 \\
\hline 10 & 9 & 0 & 1.00 & 1.00 & 1 \\
\hline 11 & 10 & 0 & 1.00 & 1.00 & 1 \\
\hline 12 & 11 & 0 & 1.00 & 1.00 & 1 \\
\hline 13 & 12 & 0 & 1.00 & 1.00 & 1 \\
\hline 14 & 13 & 0 & 1.00 & 1.00 & 1 \\
\hline 15 & 14 & 0 & 1.00 & 1.00 & 1 \\
\hline 16 & 15 & 0 & 1.00 & 1.00 & 1 \\
\hline 17 & 16 & 0 & 1.00 & 1.00 & 1 \\
\hline
\end{tabular}


For HRUs containing multiple stream reaches, the flow to each stream reach is not apportioned by stream-reach length; it is distributed equally among all reaches in the HRU. For example, flow leaving HRU ID 14 in figure $3 A$ is distributed equally among all three of the reaches within the HRU; flow is assigned to the corresponding segment associated with those reaches. Likewise, flow is distributed equally to the two parallel stream reaches in HRU_ID 10 in figure $3 B$.

Water that enters a stream in PRMS simulations (or PRMSonly GSFLOW simulations) is assumed to leave the model instantaneously. Thus, there is no groundwater recharge from streams. For watersheds in which recharge from streams is important, it could be more appropriate to represent streams by a series of cascade links that follow the course of the streams. Such an approach allows recharge along the HRUs that follow where the stream would be. This is a useful approach when estimating the spatial and temporal distribution of recharge within PRMS to be used in a separate groundwater simulation (for example, a steady-state GSFLOW simulation).

CRT has an option that allows the user to specify that some streams be ignored in the generation of cascade links. This is done with input parameter STRMFLG in the HRU CASC. DAT input file, which is used to define how streams interact with cascades. CRT allows the user to generate cascades in which the stream network is ignored (STRMFLG $=0$ ) or to generate cascades in which selected (or all) stream reaches are included (STRMFLG=1). Parameter STRMFLG allows the user to compare various stream-cascade configurations. If simulation of groundwater recharge is an important modeling objective, additional consideration of active stream reaches is warranted; see the section titled "Stream Networks and Lakes" and "PRMS Recharge Estimates" for more information on stream-network configurations.

In addition to HRU cascade links to stream segments, HRU cascade links also are defined for lakes and swales. If an HRU cascade link terminates in a lake HRU, then all flow leaving the land HRU is directed to the adjacent lake HRU (hru pet up=1.0). If an HRU cascade link terminates in a swale, then flow received by that swale only leaves the surface of the model domain through infiltration and evaporation.

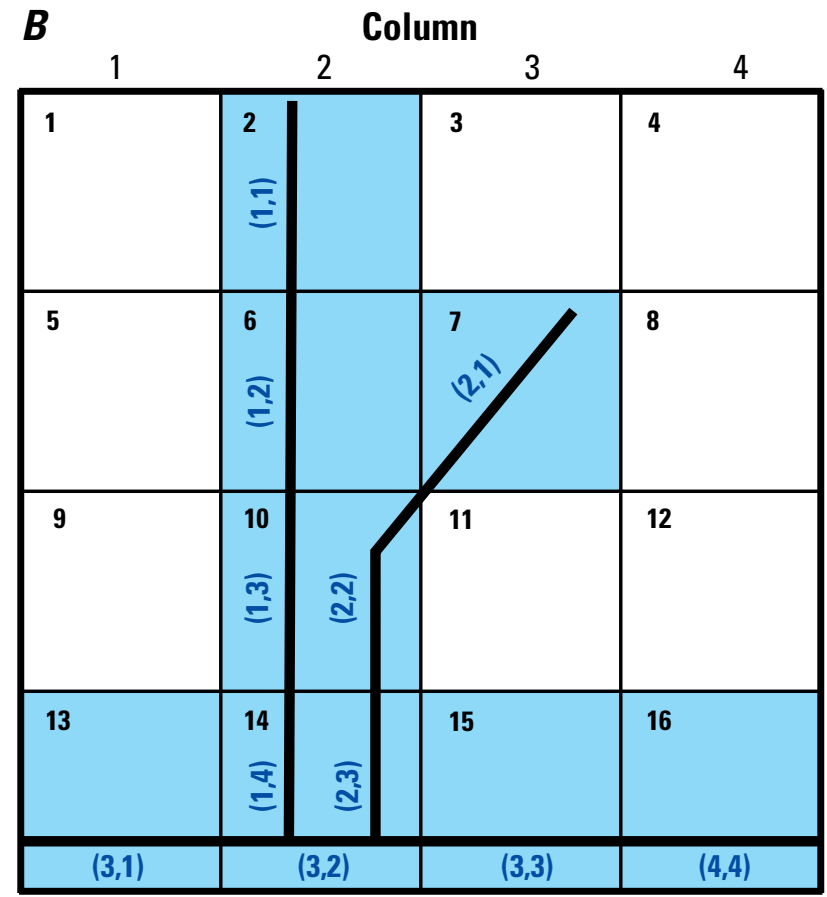

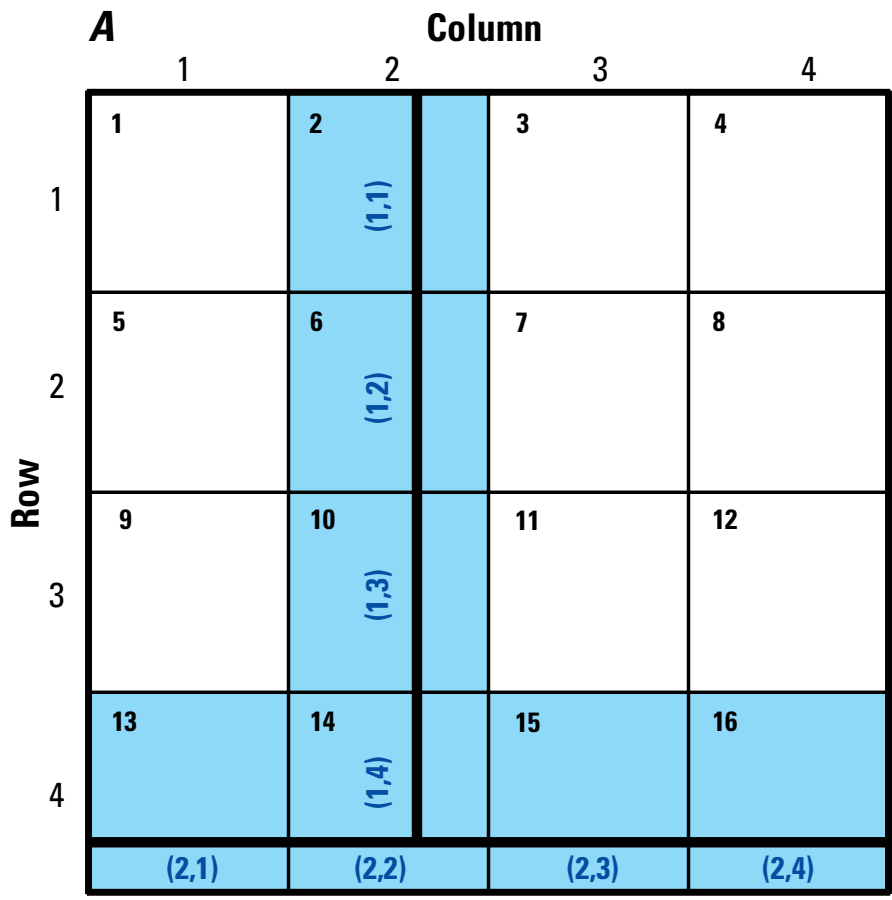

\section{EXPLANATION}

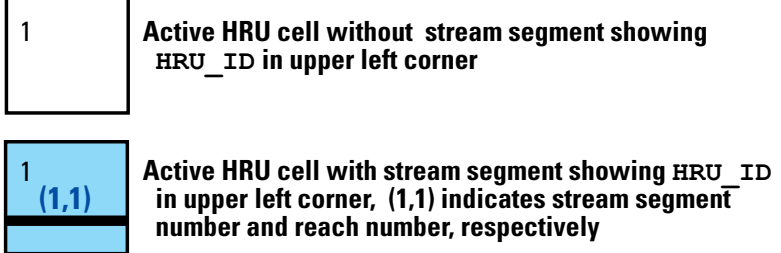

Figure 3. Hypothetical model grid with four rows and four columns illustrating different types of conditions in which multiple streams reaches can be located within a single hydrologic response unit (HRU): in $\boldsymbol{A}$, cascading flow distributed equally to the three connected reaches in HRU 14 and in $\boldsymbol{B}$, cascading flow distributed equally to the two parallel reaches in HRU 10. 


\section{CRT Fill Procedure}

Digital Elevation Model processing tools, such as those implemented in GIS software programs, are often used to process DEMs and prepare them for use in modeling applications. Many DEMs for watersheds contain local depressions or flat raster cells that can be real or an artifact of the DEM resampling procedure. While local depressions do exist, typically, they are not large enough to extend to the entire area within an HRU. Sometimes, after resampling, filling, or processing, DEMs are left with HRU or model-grid sized local depressions or pits (undeclared swales). Without correction, these undeclared swales become HRUs with no downslope cascade link and can cause numerical issues in a model if the swale does not coincide with a real feature such as a wetland, lake, or stream. Before cascades can be computed by using CRT, each HRU must have a minimum of one cascade link defined for it, unless it a designated swale, lake, or outflow HRU.

For each CRT simulation, each HRU is examined to determine if it is an undeclared swale. An HRU is an undeclared swale if it is not a swale (HRU_TYPE $=3$ ) or lake (HRU_TYPE $=2$ ), does not discharge to a stream or lake, and does not have an adjacent active HRU with a lower elevation. If undeclared swales are found in the simulation domain, a list of undeclared swales is provided in the outputstat.txt file, and the CRT Fill Procedure is recommended. The CRT Fill Procedure is an optional tool that checks for local depressions that are artifacts of DEM processing. By using methods similar to Garbrecht and Martz (1997), the CRT Fill Procedure can fill depressions so that water has a continuous flow path from high elevations to model discharge points and no undeclared swales remain. CRT Fill Procedure raises the elevation of each undeclared swale HRU by an increment specified with the parameter DPIT in the HRU_CASC.DAT input file. CRT Fill Procedure repeats this process for every HRU until no undeclared swale HRUs or circular flow paths remain. Use of the fill procedure ensures that computed cascades terminate in a designated swale, stream, lake, or outflow HRU.

The CRT Fill procedure will not adjust the elevation of active HRUs that intersect streams. If there are HRUs that are lower than all neighboring HRUs, they will not be filled by the CRT Fill Procedure if the HRU intersects a stream. These local depressions can be corrected by setting the input parameter STRMFLG $=0$ in the HRU_CASC.DAT input file and by using the CRT Fill Procedure to fill the undeclared swale HRU or by using the CRT Fill Procedure to adjust the HRU elevations before defining the stream network. If this option is selected, then the stream network should be derived on the basis of the adjusted HRU elevations provided by CRT through the outputstat.txt output file. In this case, the HRU elevations are imported into ArcGIS to develop the stream network by using the contributing area approach, for example.

\section{CRT Input}

CRT input consists of several ASCII text files. The required data for these files can be obtained from MODFLOW and PRMS input files or exported from a GIS project. CRT requires a minimum of four input files: the Cascades Definition File (HRU_CASC.DAT), which defines HRU types and includes information that controls CRT operation; SurfaceElevation File (LAND_ELEV.DAT), which defines the land-surface altitude for each HRU; Basin-Outflow Locations File (OUTFLOW_HRU.DAT), which lists the locations where lateral flow from an HRU or stream exits the model domain (outflow HRU); and Stream Locations File (STREAM_CELLS.DAT), which lists the HRUs that contain streams. Two additional input files can be included, depending on input values specified in the HRU_CASC.DAT file: HRU_ID.DAT, which is used to define HRU_IDs if they are different from the CELL_IDs, and XY.DAT, which is used for cascade visualization in A $r$ cGIS using CRV.

\section{Considerations for Preparing Input Files}

\section{HRU Discretization}

All HRUs must be square and of equal size to use all the functionality of this version of CRT. However, if the model domain is discretized into a rectilinear grid of HRUs, CRT supports the use of variable grid-cell sizes, with the exception of the FLOWFLG $=1$ option for allocating outflow fractions. In this case, gridded-HRUs must have a constant width along each row or column, but every row or column width is not required to be equal. In PRMS and GSFLOW, values associated with HRUs must be listed in a consistent order for all parameters that describe HRUs; however, the order in which HRU values are specified is arbitrary. CRT can accommodate PRMS and GSFLOW models that list input values for HRUs by using a different numbering convention (for example, excluding HRU values for inactive HRUs). CRT accommodates alternate ordering conventions for HRUs through the use of the CRT input value HRU_ID. By default, CRT assumes that CELI_IDs and HRU_IDs are the same (fig. 4A). If the grid CELL_IDs and HRU IDs are numbered differently (fig. $4 B$ ), then the HRU_ID.DAT file is required to associate the location in the grid with the HRU_ID. HRUs cannot be isolated (that is, all active HRUs must have at least one active neighboring HRU). Land elevation and HRU_TYPE input should include a value for every HRU, including lake and inactive HRUs.

\section{Boundary HRUs}

Active HRUs at model boundaries must cascade into the model domain (away from an inactive HRU at the boundary) or be defined as an outflow HRU. HRUs that are located along the edges of the active boundary must have altitudes that are greater than at least one adjacent active HRU or else be defined as a stream, outflow, or user-designated swale HRU. At least one outflow HRU must be defined for each simulation; the outflow HRU can be an HRU that contains a stream segment or an HRU where flow leaves the watershed (see, for 
example, the Sagehen Creek Basin application) or a surface feature in a closed basin (see, for example, the Lower Walker River Basin application).

\section{Land-Surface Depressions and Swales}

It is recommended that the DEM be resampled, filled, and aligned with the gridded-HRUs in the model domain to develop the land-surface elevation model for each simulation. The land-surface elevation model can be examined for undeclared swales by using information from the outputstat. txt file or visualization by using CRV. If there are undeclared swales in the model or if CRT does not converge to a solution within the iteration limits imposed by the parameter OUTITMAX in the HRU_CASC.DAT input file, the CRT Fill Procedure can be employed to prepare the land surface for generation of cascades. The Fill Procedure can be employed by executing CRT with the IFILL input parameter set to 1 in the HRU_CASC.DAT input file.

To declare an HRU as a swale, set the value for HRU TYPE $=3$ in the HRU_CASC.DAT input file. If the CRT Fill Procedure is employed in a CRT simulation, elevations

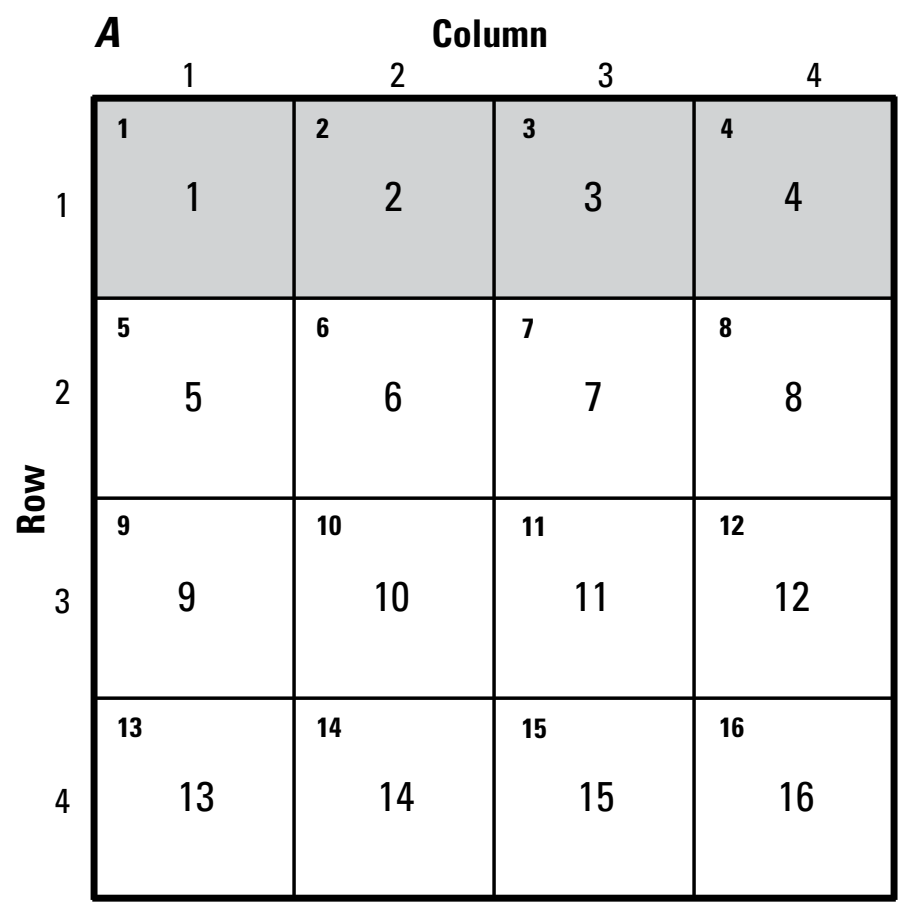

EXPLANATION

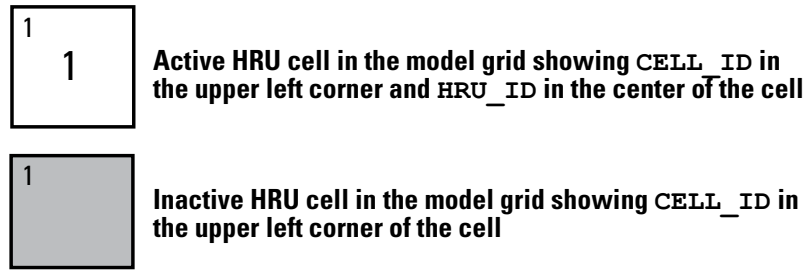

of designated swales, reservoir, or lake HRUs will not be processed. If the model domain contains a closed basin, an outflow HRU will need to be defined where lateral flow can collect. For example, in a closed basin with a lake, the lake outflow HRU should be coincident with the lake desiccation point or centroid.

\section{Stream Networks and Lakes}

It is recommended that the entire user-defined stream network is used to compute cascades (STRMFLG=1 and ON_OFF=1); however, users could want to examine the effects of excluding selected streams on cascades or PRMSonly outputs (for example, ephemeral reaches), which requires an advanced configuration of streams. CRT offers the flexibility to exclude all streams (STRMFLG $=0$ ) or include selected streams (STRMFLG=1). When the parameter STRMFLG=0, the stream network defined in the STREAM_CELLS.DAT input file is not used, and cascades are routed through HRUto-HRU cascade links only. When the parameter STRMFLG=1, the ON_OFF parameter in the STREAM_CELLS.DAT file indicates whether land HRUs adjacent to or intersecting

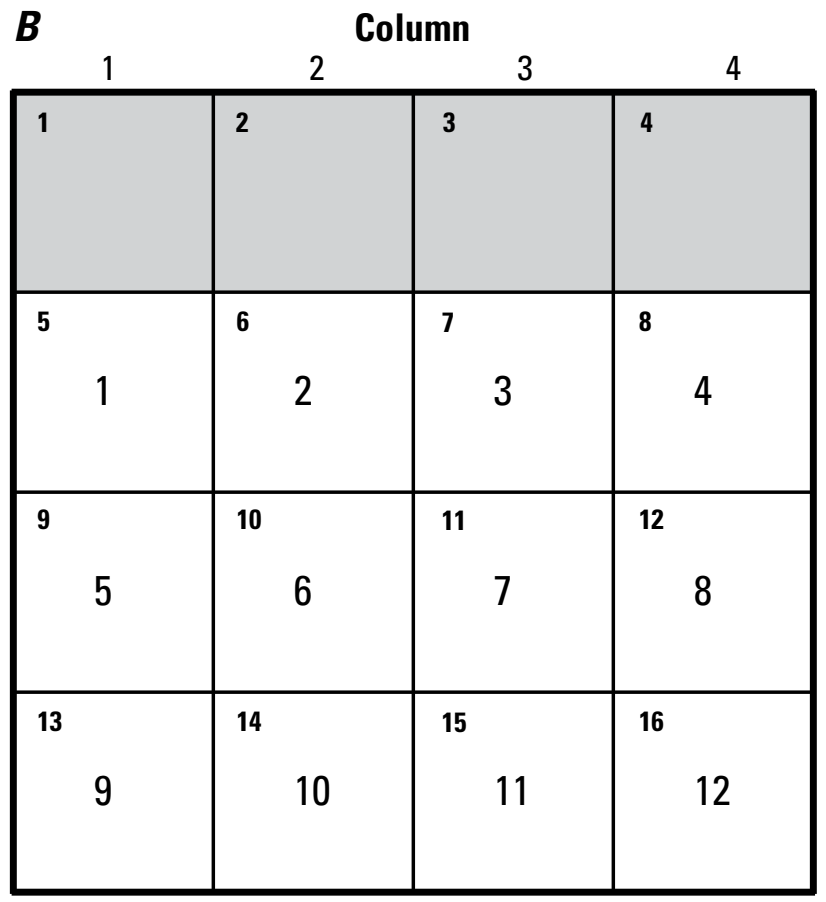

Figure 4. Hypothetical model grid with four rows and four columns showing $\boldsymbol{A}$, a case in which hydrologic response unit identifications (HRU_IDS) and grid cell identifications (CELI_IDS) are equivalent and $\boldsymbol{B}$, a case in which HRU_IDs and CELL_IDS are numbered differently. 
streams will discharge to the stream reach (ON_OFF=1); in that case, flow entering the stream network is assumed to leave the model instantaneously for PRMS simulations or it is routed through the stream network for GSFLOW simulations. When the parameter ON_OFF $=0$, excluded streams are designated as land HRUs. Cascade links continue downslope from land HRU to land HRU, active stream, lake, or outflow HRU.

Applications of CRT that contain lakes or reservoirs require additional consideration when constructing the HRU_CASC. DAT input file. HRUs that contain a lake must have their HRU_TYPE set to a value of 2 . When a cascade link terminates at a lake HRU, all of the flow from the upslope HRU is given to the first adjacent lake HRU (hru_pct_up=1.0), and no more cascade links are computed for the upslope HRU. Furthermore, if an HRU contains both a stream and lake, all cascading flow is given to the lake. Moreover, cascade links are not generated between the outermost HRUs representing a lake and the inner HRUs of the lake. If the simulation is of a closed basin (no surface outlet), then the outflow HRU should be active and coincident with the lake desiccation point. Figure 5 shows an excerpt of one of the HRU_CASC.DAT input files for the Lower Walker River Basin application that illustrates how to define the HRU_TYPE for a lake.

\section{Groundwater Cascades}

By default, groundwater and surface-water cascades generated by CRT are the same (ncascade=ncascdgw); however, CRT offers the flexibility to generate separate cascades for both domains. This can be done by replacing the LAND_ELEV array in the LAND_ELEV.DAT input file with the steady-state groundwater head distribution and re-running CRT. If the number and locations of active groundwater HRUs differ from the surface cascades, then the HRU_CASC.DAT input file must be modified to represent the correct number and locations of groundwater HRUs. In order for CRT to compute groundwater cascades, all groundwater HRUs should have at least one adjacent active cell. Make sure to save the cascade.param file to another directory before re-running CRT to generate separate groundwater cascades because the information in the cascade.param file for surface cascades will be overwritten with the groundwater cascade information. The groundwater_cascade.param output file will contain the groundwater-cascade information.

$\begin{array}{lllllll}2 & 1 & 1 & 1 & 1 & 1 & 1 \\ 1 & 2 & 1 & 1 & 1 & 1 & 1 \\ 1 & 2 & 2 & 1 & 1 & 1 & 1 \\ 1 & 2 & 2 & 2 & 1 & 1 & 1 \\ 1 & 2 & 2 & 2 & 2 & 1 & 1 \\ 1 & 2 & 2 & 2 & 2 & 2 & 2 \\ 1 & 2 & 2 & 2 & 2 & 2 & 2\end{array}$

Figure 5. Excerpt from the Lower Walker River Basin sample application 2A HRU_CASC.DAT file showing definition of lake hydrologic response units by using HRU_TYPE $=2$.
If groundwater cascades are generated separately from the surface cascades, and on the basis of the HRU elevation grid or an externally derived groundwater-head distribution, then users can use the CRT Fill Procedure to ensure that that all cascades terminate at a stream or other cascade discharge feature. If swales exist in the HRU elevation grid or groundwater-head distribution that is used to develop the groundwater cascades, then the HRU_CASC.DAT input file should be modified to remove all local depressions, and CRT can be executed to generate groundwater cascades. To use the CRT Fill Procedure for generating groundwater cascades, set the value IFILL $=1$ in the HRU_CASC.DAT file and set the value for DPIT to a smaller value, such as 0.01 , which ensures that the CRT Fill Procedure tolerance reflects potentially smaller differences in groundwater-head elevations between HRUs. Groundwater cascades to or from lake HRUs can be complex. If the CRT Fill Procedure is used to facilitate computation of groundwater cascades in a simulation with lakes, an outflow HRU at the center of the lake is recommended. Verify cascades afterward to ensure that all groundwater cascades coincident with the lake cascade in the direction defined by the original groundwater heads.

\section{PRMS Recharge Estimates}

Often, determining the location and rates of groundwater recharge is an important objective of numerical simulations. Special consideration is required when developing cascades for PRMS simulations to estimate spatial and temporal variations in recharge. PRMS does not simulate recharge from streams, and any flow that enters a stream leaves the model instantaneously; however, in many cases, streams are an important source of recharge in a watershed. Recharge from the stream network can be enhanced in dry or losing areas. There can be significant groundwater recharge through the unsaturated zones under a streambed because streams are not always in hydrologic connection with the groundwater. Recharge from streams can be simulated in PRMS simulations by representing streams as a series of cascade links that follow the stream. In this case, deep percolation from the HRUs representing the stream can be used to approximate stream recharge, and the amount of recharge can be adjusted through the PRMS parameter ssr2gw_rate (Markstrom and others, 2008, p. 59)

If PRMS is being used to estimate recharge in a watershed, then cascades can be created to represent streams by using the STRMFLG and ON_OFF input parameters. Not all streams produce recharge, such as gaining stream reaches, for example. If the entire stream network is generally gaining, then the parameter STRMFLG should be set to 1, which will include streams defined in the STREAM_CELLS.DAT input file for generating cascades. If all streams provide recharge (entire stream network is losing), all stream reaches can be removed from cascade computation by setting the parameter STRMFLG to 0 in the HRU_CASC.DAT file. If the recharge behavior of the stream network is spatially variable, individual reaches can be 
selected from the stream network during cascade computation by using the ON_OFF input parameter. Streams that produce recharge should be removed from the STREAM_CELLS. DAT file by setting the ON_OFF parameter to 0 , which allows those stream segments to be represented by a series of HRU-to-HRU cascade links instead of stream segments.

\section{Cascades-Definition File (HRU_CASC.DAT)}

The cascades-definition input file (HRU_CASC.DAT) is used to define several options for how CRT will calculate cascades and report them to the output files. The file is also used to specify the HRU TYPE of each HRU in the model domain. Item 1 is a single line of values. Item 2 is a 2 -dimensional array of integer values with a defined input format described below.

Item 1. HRUFLG STRMFLG FLOWFLG VISFLG IPRN IFILL DPIT OUTITMAX

HRUFLG

An integer value that indicates whether the HRU identifiers (HRU IDs) are numbered the same as grid-cell identifiers CELL_IDS starting in the upper left-hand corner of the grid, with CELL_IDs increasing sequentially across columns in a single row and then continuing again on the left-hand side of a new row. A value of HRUFLG $=0$ indicates that the numbering of HRU_ID is equivalent to CELL ID. A value of HRUFLG $=1$ indicates that CELL_IDs are defined according to values listed in the input file HRU_ID.DAT defined later in this report.

STRMFLG An integer value that indicates how CRT interacts with streams during cascade generation. A value of STRMFLG $=0$ indicates that no stream reaches will be included in cascades; only HRU-to-HRU and HRU-tooutflow HRU cascade links occur. A value of STRMFLG=1 (which is recommended) indicates that selected stream reaches will be included in the computation of cascades; for this option, parameter ON_OFF in the STREAM_CELLS.DAT input file defines which stream reaches will be considered.

FLOWFLG An integer value that indicates how outflow fractions will be calculated. A value of FLOWFLG $=0$ indicates that flows will be apportioned evenly among the number of outflow cascade links; a value of FLOWFLG=1 indicates that the outflow fractions will be calculated on the basis of relative slopes among the outflow cascade links (equation 1).
VISFLG

IPRN

IFILL

DPIT

OUTITMAX

An integer value equal to the maximum number of CRT Fill Procedure iterations. A large number such as 10,000 is suggested.

Item 2. HRU_TYPE

HRU_TYPE An array of dimension number of rows (NROW) by the number of columns (NCOL) that specifies the type of HRU (integer values) for each gridded-HRU: 0 is an inactive HRU, 1 is a land HRU, 2 is a lake HRU, and 3 is a swale HRU. Input is read line by line, in which each line has NCOL values and there are NROW lines. All values for a given row must be on one line. 


\section{Surface-Elevation File (LAND_ELEV.DAT)}

The surface-elevation input file (LAND_ELEV.DAT) is used to define the numbers of rows and columns in the model grid and the land-surface elevation of each HRU. It is not necessary to specify the size of each HRU; the program assumes that all HRUs are square and of equal size.

Item 1. NROW NCOL

NROW An integer value that indicates the number of rows in the model grid.

NCOL An integer value that indicates the number of columns in the model grid.

Item 2. LAND_ELEV

LAND_ELEV An array of dimension NROW by NCOL that specifies land-surface elevations (real values) for each HRU. Input is read line by line, in which each line has NCOL values and there are NROW lines. All values for each row must be on the same line.

\section{Basin-Outflow Locations File (OUTFLOW HRU.DAT)}

The basin-outflow-locations input file (OUTFLOW_HRU. DAT) is used to define the number and identifier of the outflow HRUs in the model grid. Outflow HRUs are those that receive inflow cascade links but that have no outflow cascade links. A minimum of one outflow HRU must be defined to compute cascades by using CRT. Two examples of outflow HRUs are (1) an HRU on the edge of the model grid and having no outflow cascade (the HRU may or may not contain a stream) and (2) an HRU at the center of a lake in a closed basin.

\section{Item 1. NUMOUTFLOWHRUS}

NUMOUTFLOWHRUS An integer value that indicates the number of outflow HRUs in the grid.

Item 2. Item 2 is repeated NUMOUTFLOWHRUS times: OUTFLOW_ID ROW COL

OUTFLOW_ID An integer value that indicates the outflow HRU identifier.

ROW

An integer value that indicates the row identifier for the outflow HRU.

COL

\section{Stream-Locations File (STREAM_CELLS. DAT)}

The stream-locations input file (STREAM_CELLS.DAT) is used to specify HRUs that intersect streams, identifiers for each stream reach and stream segment, and a flag that defines whether a reach will be included in the generation of cascades. The length of a stream within an HRU is called a reach, and a group of one or more reaches that typically span one or more HRUs is called a segment. If a Stream Flow Routing Package GSFLOW input file (SFR2; Niswonger and Prudic, 2005) has already been prepared, it will contain much of the information needed to create the STREAM_CELLS.DAT CRT input file.

Item 1. NREACH

NREACH An integer value that indicates the total number of stream reaches in the grid.

Item 2. Item 2 is repeated NREACH times:

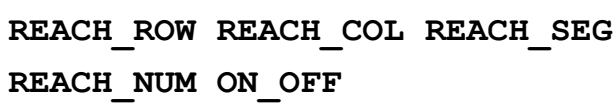

REACH_ROW An integer value that indicates the row identifier for the HRU containing the reach.

REACH_COL An integer value that indicates the column identifier for the HRU containing the reach.

REACH_SEG An integer value that indicates the segment number of the reach.

REACH NUM An integer value that indicates the reach number of the reach within the segment. This value ranges from 1 to the total number of reaches with the segment.

ON_OFF

\begin{abstract}
An integer value that indicates whether the reach will be considered in the generation of cascades: a value of $\mathbf{O N} \mathbf{O F F}=0$ indicates the reach will not be included in cascade computation, and a value of ON_OFF $=1$ indicates that the reach will be included.
\end{abstract}

\section{Optional Files}

CRT has two optional input files: a file containing HRU identifiers that is used when HRU data are specified in an order that differs from the default convention (file HRU_ ID.DAT) and a file that describes the coordinates of the centroid of each HRU for the purpose of visualizing cascades by using CRV (file XY.DAT). 


\section{HRU-Identifiers File (HRU_ID.DAT)}

This file describes the relation between HRU identifiers (HRU_IDs) and grid-cell identifiers (CELL_IDs) if HRU information does not follow the standard convention. In the standard convention, grid-cell numbering starts with a value of 1 in the upper left HRU of the model grid and continues across the top row of HRUs; numbering continues from left to right in each subsequent row. Although this input file allows HRU information to be ordered in a non-standard format, HRUs must be square and of equal size or conform to the discretization outlined in the section titled "HRU Discretization". This file is required when the parameter HRUFLG $=1$ in the HRU_ CASC.DAT input file.

Item 1. NUMACTIVE

NUMACTIVE An integer value that indicates the number of active HRUs. HRUs are made inactive by setting parameter HRU_TYPE $=0$ in file HRU_CASC.DAT

Item 2. Item 2 is repeated NUMACTIVE times: HRU_ID CELL_ID

HRU_ID An integer value that indicates the HRU_ID used to index HRUs

CELI_ID An integer value that indicates the corresponding grid-cell ID

\section{Cascade-Visualization File (XY.DAT)}

This file provides the coordinates for the centroid of each HRU to facilitate visualization in ArcGIS. This file is required when VISFLG=1 in the HRU_CASC.DAT input file. The total number of HRUs ( $\mathrm{nhru}$ ) is equal to the number of rows (NROW) multiplied by the number of columns (NCOL) in the model domain. The horizontal and vertical datums that define the coordinate system should be coincident with any GIS data sets used to create the model so that cascade visualization is coincident with model features such as the DEM and stream network.

Item 1 . Item 1 is repeated (nhru times):

$$
\text { HRU_ID X_LOC Y_LOC }
$$

HRU_ID An integer value that identifies the HRU_ID.
X_LOC
$\begin{aligned} & \text { A real value that indicates the X-coordinate of } \\ & \text { the centroid of HRU_ID. }\end{aligned}$
Y_LOC
$\begin{gathered}\text { A real value that indicates the y-coordinate of } \\ \text { the centroid of HRU_ID. }\end{gathered}$

\section{Installing and Running CRT}

CRT is an executable program developed for 32-bit and 64-bit Windows Operating Systems. To run the program, copy the executable file (CRT.exe) into a directory that contains the ASCII input files required for CRT operation. The program can then be run by either double-clicking on the executable file or by typing the command CRT.exe within a DOS Command Prompt window that has been directed to the directory housing the data files. During program execution, a window will appear that provides run-time information about program execution and then closes once computation of cascades has been completed. More information about CRT installation and operation is located in a readme.txt file distributed with the software.

\section{Output Files}

A total of eight files are always created as part of a CRT run. In addition, one optional file can be created to visualize cascades by using CRV, depending on an option specified in the input files. The output files include files to verify cascades and input files for PRMS and GSFLOW cascade modules. Each of the output files that are created by CRT are described in following sections.

\section{CRT Program Summary File (outputstat.txt)}

This file provides information on the CRT run, including options selected, input data, error messages, a list of undeclared swales, and a program summary. If the CRT Fill Procedure is selected ( IFILL=1), then the outputstat.txt file will include land-surface models before and after CRT operation, elevation differences between land surface models, and the CRT Fill Procedure Summary. A list of undeclared swale HRUs is provided in the outputstat.txt file when the value for IFILI is specified as 0 in the HRU_CASC.DAT input file.

\section{Upslope Connections File (hru_up_id.out)}

This file consists of a column of integers with ncascade entries that are the HRU identifiers of upslope HRUs for each cascade link - that is, PRMS/GSFLOW Cascade Module parameters hru_up_id or gw_up_id. Each HRU can have up to four cascade links; therefore, the output file can have up to four values for each HRU_ID.

\section{Downslope Connections File (hru_down_ id.out)}

This file consists of a column of integers with ncascade entries that are the HRU identifiers for downslope HRUs for each cascade link - that is, PRMS/GSFLOW Cascade Module parameters hru_down_id and gw_down_id. Each HRU can have up to four cascade links; therefore, the output file can have up to four values for each HRU_ID. If an HRU discharges to a stream segment, the corresponding value in hru_down_id.out is set to 0 . 


\section{Cascade Link Outflow-Fraction File (casc_pct. out)}

This file consists of a column of real numbers with ncascade entries, each of which indicates the fraction of flow routed from an HRU to each downslope HRU along each of the cascades links. File casc_pet.out defines PRMS/GSFLOW Cascade Module parameters hru_pct_up and gw_pct_up. Each HRU can have up to four cascade links; therefore, the output file can contain up to four values for each HRU.

\section{Stream Segment Cascade Link File (hru strmseg_down_id.out)}

This file consists of three columns of integers. The first column specifies whether or not an HRU discharges to a stream or to another HRU and corresponds with the PRMS/GSFLOW Cascade Module parameters hru_strmseg_down_id and gw_strmseg_down_id. If an $\bar{H} R U$ discharges to a stream, the value shown in the first column will be the stream segment number; if an HRU does not discharge to a stream, the value shown will be 0 . If the downslope connection is a stream segment (hru_strmseg_down_id >0), then the second and third columns indicate the row and column identifiers of the HRU containing the reach within the stream segment that receives flow from the upslope HRU. The row and column indicators are not used by PRMS or GSFLOW but are included to aid in the evaluation and verification of cascades.

\section{PRMS/GSFLOW Cascade Parameter Input Files}

Output generated by CRT is written to three files that can be used directly in PRMS and GSFLOW Parameter Files without further modification. These three files are the parameter dimensions file (parameter_dimensions.txt), which provides dimension data for cascade parameters, and the surface cascades (cascade.param) and groundwater cascades (groundwater_cascade.param) input files, which provide all of the cascade parameter data. The general input format used by the PRMS and GSFLOW models for definition of parameter dimensions and parameter values, and the control file modifications required to incorporate cascade input generated by CRT, is described later in this report and in greater detail in Markstrom and others (2008, p. 142-147). Specific examples of output generated by CRT are provided in the sample applications.

The general form of dimension parameters specified for PRMS and GSFLOW is as follows:

\# \# \# \#

NAME

SIZE
The first line is used as a delimiter for each of the dimension declarations, specified as a string of four pound signs (\#\#\#\#). The second line (NAME) is the name of the dimension, which is specified as a character string without spaces and in lowercase text. For cascade parameters, NAME will be either ncascade or ncascdgw. The third line (SIZE) is the dimension size, specified as an integer value; for cascade parameters, SIZE will be equal to the number of cascade links.

Parameter values specified for PRMS and GSFLOW have the following seven components:

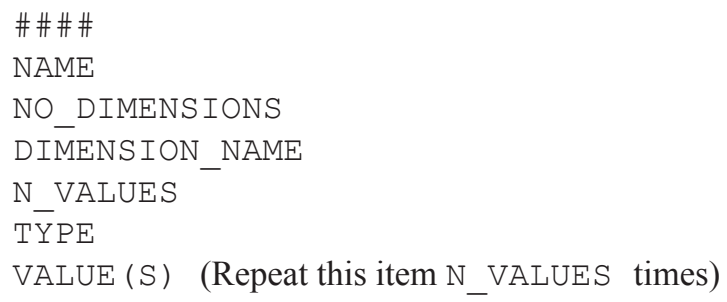

The first line is used as a delimiter for each parameter read by PRMS and GSFLOW, and is specified as a string of four pound signs (\#\#\#\#). The second line (NAME) is the name of the parameter, which is specified as a character string without spaces and in lowercase text. The third line (NO_DIMENSIONS) is used to set the number of dimensions that define the array used to store the parameter values. NO DIMENSIONS is specified as an integer value, which is equal to 1 for ncascade and ncascdgw in this case. The fourth line (DIMENSION_NAME) is the name of a one-dimensional array, which for CRT is either ncascade or ncascdgw. The next line specifies an integer value equal to the number of values (N_VALUES) that are input for the parameter. The sixth line specifies the type (TYPE) of the parameter values as an integer value; options are the following:

1 for integer.

2 for real (single-precision, floating decimal point).

3 for double (double-precision, floating decimal point).

4 for character string.

Only options 1 and 2 are used in the cascade-parameters files. The line following TYPE is the first parameter value and is repeated N_VALUES times.

\section{Cascade Parameter Dimension File (parameter_ dimensions.txt)}

This file contains the values of the dimension parameters ncascade and ncascdgw calculated by CRT. The structure 
of the file is described in the previous section. By using an example of ncascade $=$ ncascdgw $=6,100$, the parameter_dimensions.txt file, for example, would have the following structure:

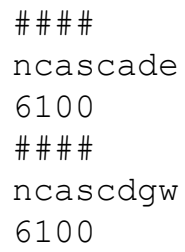

To add these dimension parameters to the primary PRMS or GSFLOW Parameter File, open the Parameter File in a text editor and paste the contents of parameter_dimensions.txt into the file after the line that contains the character string " $\star \star *$ Dimensions $* *$," which is typically located on the third line of the primary Parameter File. There should only be one line with the parameter delimiter (\#\#\#\#) between the pasted data and the next line of the input file.

\section{Surface and Groundwater Cascades Input Files (cascade.param and groundwater_cascade. param)}

The files cascade.param and groundwater_cascade. param include all of the information needed for surface and groundwater cascades, respectively, for a PRMS or GSFLOW simulation. Examples of the formatting used in these files are provided here for parameters hru_up_id (in the cascade. param file) and gw_pct_up (in the groundwater_cascade. param file):

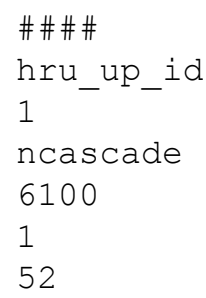

and

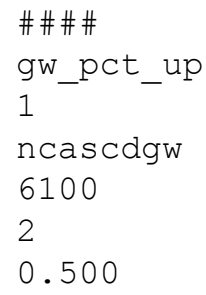

The number of values calculated by CRT for ncascade and ncascdgw for the two examples is 6,100 . The first value shown for hru_up_id is 52, and the first value for gw_pct_up is 0.500 .

Data in the cascade.param and groundwater_cascade. param files can be read by PRMS and GSFLOW in one of two ways. First, the data can be cut and pasted into an existing Parameter File that has been specified in the PRMS or GSFLOW Control Files by using parameter param_file (see Markstrom and others, 2008, p. 134-139). Alternatively, data in the two files can be read directly from the files generated by CRT by including the pathname of the files in the definition of param file in the PRMS or GSFLOW Control Files. For example, in a typical GSFLOW simulation most parameter data is contained in the Parameter File, 'gsflow.params'. Additional cascade parameter data from the files cascade.param and groundwater_cascade.param can be accessed by using the following input format for parameter param file in the GSFLOW Control File:

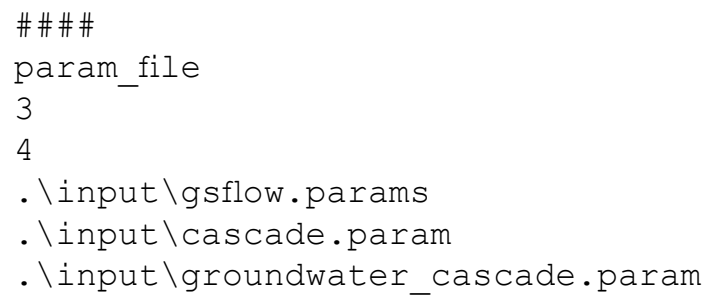

The third line of this example input block indicates that 3 Parameter Files will be used to define input data for the simulation. The path names for each of the Parameter Files are then listed after the line showing a value of 4 , which refers to the fact that the 'value' of the path names are of type character (refer to the PRMS and GSFLOW input instructions provided in Markstrom and others, 2008, p. 134-139).

\section{CRV Input File (vis.txt)}

This optional output file consists of a table of comma separated values used for visualization of cascades with the CRV program. Each row in the table represents a single cascade link. The column headings and order of the data provided in the file is as follows:

CASCADE_ID: The values in this column define the cascadelink identifier (CASCADE_ID) used to index each HRU cascade link.

HRU_UP_ID: The values in this column define the HRU_ID of the upslope connection in a cascade link.

CASCADE_TYPE_UP: The values in this column define the type of cascade of the upslope HRU in the link as determined by CRT. A value of 1 indicates an active land HRU, 2 indicates a lake HRU, 3 indicates a swale HRU, and 4 indicates an HRU that contains a stream or is defined as an outflow HRU in the OUTFLOW_HRU.DAT input file. 
UP ROW: The values in this column define the row identifier of the hru_up_id. Row identifiers for each HRU_ID are assigned according to the default convention (top to bottom) as input is read by CRT or can be specified by using the HRU_ID.DAT input file.

UP_COL: The values in this column define the column identifier of the hru_up_id. Column identifiers for each HRU ID are assigned according to the default convention (left to right) as input is read by CRT or can be specified by using the HRU_ID.DAT input file.

UP X: The values in this column define the X-coordinate location for the centroid of hru up id. Coordinate locations for each HRU_ID are defined in the XY.DAT input file. The coordinate system and datum are user-defined.

UP_Y: The values in this column define the Y-coordinate location for the centroid of hru_up_id. Coordinate locations for each HRU_ID are defined in the XY.DAT input file. The coordinate system and datum are user-defined.

HRU_DOWN_ID: The values in this column define the hru down_id for each cascade link. If the downslope link is an HRU, this value is the HRU_ID of the downslope connection in a cascade link. If the downslope link is a stream segment, then the hru_down_id describes the location of the HRU that contains the stream reach contributing flow to that segment.

CASCADE_TYPE_DOWN: The values in this column define the type of cascade of the downslope HRU in the link as determined by CRT. A value of 1 indicates an active land HRU, 2 indicates a lake HRU, 3 indicates a swale HRU, and 4 indicates an HRU that contains a stream or is defined as an outflow HRU in the OUTFLOW_HRU.DAT input file.

DOWN_ROW: The values in this column define the row identifier of the HRU corresponding to hru_down_id. Row identifiers for each HRU_ID are assigned according to the default convention (top to bottom) as input is read by CRT or can be specified by using the HRU_ID.DAT input file.

DOWN_COL: The values in this column define the column identifier of the hru_down_id. Column identifiers for each HRU_ID are assigned according to the default convention (left to right) as input is read by CRT or can be specified by using the HRU_ID.DAT input file.

DOWN_X: The values in this column define the X-coordinate location for the centroid of hru_down_id. Coordinate locations for each HRU_ID are defined in the XY.DAT input file. The coordinate system and datum are user-defined.

DOWN_Y: The values in this column define the Y-coordinate location for the centroid of hru_down_id. Coordinate locations for each HRU_ID are defined in the
XY.DAT input file. The coordinate system and datum are user-defined.

CASC_PCT: The values in this column define the fraction of flow that is routed along a cascade link from the HRU_ID defined by hru_up_id to the HRU_ID defined by hru_down_id.

HRU_STRM_SEG_DOWN: For HRUs that discharge to a stream segment (hru_strmseg_down_id greater than 0 ), the values in this column refer to the HRU that intersects the stream segment; otherwise the value is 0 .

\section{Cascade Routing Visualization}

The Cascade Routing Visualization (CRV) toolbox has been developed to visualize and verify the cascade links and cascade features generated by CRT. CRV takes the CRT output file vis.txt and uses ESRI's ArcGIS functionality to visualize CRT output for verification of HRU cascade types and cascade links (cascade features). CRV also applies symbology to these cascade features to enhance the visualization of the cascading flow. It is assumed in the following discussion that the reader is familiar with ArcGIS functionality.

\section{Cascade Features}

Cascade features include cascade links, which are represented as line features connecting the upslope HRUs to downslope HRUs. The line feature begins at the X-Y location of the hru_up_id cell center and ends at the X-Y location of the hru_down_id cell center (fig. 6). The coordinate system and datum are user-defined. A unique ID (CASCADE_ID) and the percentage of flow (CASC_PCT) are included as attributes of the output cascade-link line feature.

Cascade types are visualized as point features representing lakes, designated swales, streams or outflow, and undeclared swales. The value of each cascade type is stored in the CRV output attribute CASCADE_TYPE. CASCADE_TYPEs 2, 3, or 4 (lakes, designated swales, or stream or outflow HRU, respectively, as shown in table 3 , are based on parameters CASCADE_TYPE_UP and CASCADE_TYPE_DOWN given in vis.txt. $\overline{C A S C A} \overline{D E}$ TYPE 5 is assigned by $\bar{C} R V$ to undeclared swales. Undeclared swales are HRU_IDs that are active (CASCADE_TYPE_UP or CASCADE_TYPE_DOWN=1), but have been identified by CRT as undeclared swales and are not identified as swales in the CASCADE TYPE DOWN column in vis.txt. All cascade-type point features are created from the X-Y location of the cell center (fig. 6). A unique ID (HRU_ID) and cascade type (CASCADE_TYPE) are included as attributes of the output cascade-type point feature.

Cartographic representations are used to symbolize the cascade features. Cartographic representations use rules to define how CRT output data are symbolized. Representations are stored in an ESRI file geodatabase as a feature-class attribute. Cartographic representations require an ESRI ArcEditor 
license at minimum (ESRI, 2011). The cascade-link line features are represented as arrows of varying thickness and color based on the percentage of flow from each upslope to each downslope cell HRU. The cascade-type point features are represented as circles with different colors based on type.

Rules were established within the CRV to define an arrow for each unique value of cascade flow percentage. The arrows increase in thickness and change in color as the percentage of flow increases (fig. 7). The rules are assigned to the features on the basis of the values in the CASC_PCT attribute. The FLOWFLG parameter in HRU_CASC.D.DAT is used to determine the number of flow values shown on the visualization: for FLOWFLG $=0$, a maximum of four values is shown $(25$, 33,50 , and 100 percent); for FLOWFLG $=1$, a maximum of six values is shown $(25,33,50,66,75,100$ percent). The percentage values shown in CRV for FLOWFLG $=1$ are based upon ranges of CASC_PCT attribute values categorized for visualization as follows: values greater than 0.0 and less than or equal to $0.29(25)$, values greater than 0.29 and less than or equal to 0.415 (33), values greater than 0.415 and less than or equal to $0.58(50)$, values greater than 0.58 and less than or equal to 0.705 (66), values greater than 0.705 and less than or equal to 0.875 (75), and values greater than 0.875 and less than or equal to $1.0(100)$.
A rule was defined for each unique cascade type: lake, swale, and stream or outflow HRU. The different colors of the circles are based on the cascade type (fig. 7). The rules are assigned to the features on the basis of the values in the CASCADE TYPE attribute. Only cascade links defined in the vis.txt file will be displayed.

Cascade features can be generated by CRV either by importing a pre-existing vis.txt file or by executing CRT within CRV. CRV creates the cascade-links feature class

Table 3. Comparison of CRT output parameters CASCADE TYPE_UP and CASCADE_TYPE_DOWN and CRV output feäture class attribute CASCADE_TYPE.

[CRT, Cascade Routing Tool; CRV, Cascade Routing Visualization; HRU, Hydrologic Response Unit]

\begin{tabular}{ccl}
\hline $\begin{array}{c}\text { CASCADE_TYPE_- } \\
\text { UP and CASCADE } \\
\text { TYPE_DOWN }\end{array}$ & $\begin{array}{c}\text { CASCADE } \\
\text { TYPE }\end{array}$ & \multicolumn{1}{c}{$\begin{array}{c}\text { CASCADE_TYPE } \\
\text { description }\end{array}$} \\
\hline 1 & - & Land \\
2 & 2 & Lake \\
3 & 3 & Declared swale \\
4 & 4 & Stream or outflow HRU \\
& 5 & Undeclared swale \\
\hline
\end{tabular}

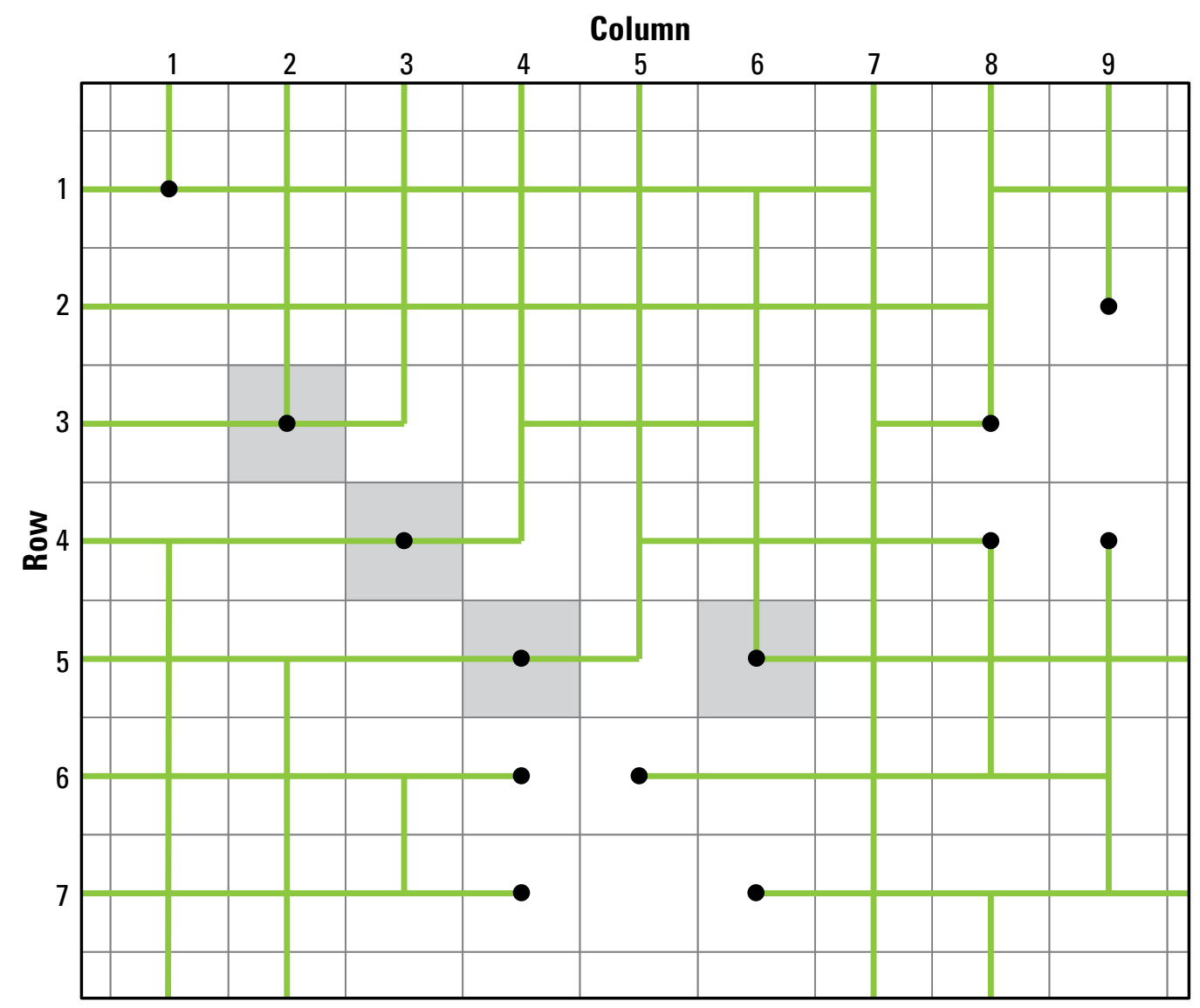

\section{EXPLANATION}

Stream-segment cell Cascade-link line feature Model grid-cell boundary Cascade-type (CASCADE_TYPE) point feature
The cells intersecting stream segments and model grid cells are shown for reference and were not generated by CRV

Figure 6. Diagram showing Cascade Routing Visualization (CRV) generated hypothetical cascade links (as line features connecting cell centers) and cascade types (CASCADE_TYPEs) (as point features). 
(CascadeFlow_XX) and cascade-types feature class (CascadeType_XX) in a file-based geodatabase (CRV_XX.gdb) within a folder named CRV_XX, where $\mathrm{XX}$ is a number that identifies each subsequent execution of CRV. For example, the first time CRV uses a new workspace to generate visualization data, a new folder will be created in the directory called CRV_1. The folder CRV_1 will contain feature-class files CascadeFlow_1, CascadeType_1, and CRV_1.gdb, along with the input files CRT used to create that version of the vis.txt input file (if the vis.txt file was not imported into CRV). Each subsequent execution of CRV will create an additional folder, and the value for XX in the file names will be incremented.

CRV uses points and arrays to construct cascade-link lines for all the records in the input vis.txt file. CRV uses points to create cascade-type points for each HRU_ID with a CASCADE_TYPE value. CRV applies the symbology to the cascade features. CRV creates the cartographic representations and assigns the rules by using ArcGIS Cartography tools. CRV adds these feature classes to the current ArcMap document.

\section{Installing and Using CRV}

CRV is an ArcGIS python toolbox used to execute CRT and visualize the CRT output. CRV requires the CRT output file, vis.txt, to run, and, as described in the previous section, the vis.txt file can be generated by running CRT within CRV or by accessing a previously generated vis.txt file. CRV is designed to be accessed by using ArcGIS Desktop software (version 10.0). CRV is built on top of standard functionality included in ArcGIS Desktop running at the ArcEditor license level. It is necessary to uninstall all previous versions of CRV before installing a new version of the software. The ArcGIS CRV toolbox can be accessed the same way standard ArcGIS tools are used: double-click on the name of the toolbox, or right click the toolbox to access its properties or documentation. CRV will run CRT to compute cascades or use the user provided vis.txt file. CRV will display the results in the current ArcMap document, where users can verify cascades. If cascades need to be modified, CRT input can be adjusted, and CRV can re-execute CRT to recompute cascades. More detailed instructions for installing and running CRV are provided in a readme file with the software.

\section{Sample Applications}

Two sample applications are provided to illustrate how CRT input can be modified to generate cascades for watersheds with a variety of hydrological, topographical, and topological conditions. The two sample applications are for the Sagehen Creek Basin, California (application 1A and 1B), and the Lower Walker River Basin, Nevada (applications 2A, 2B,

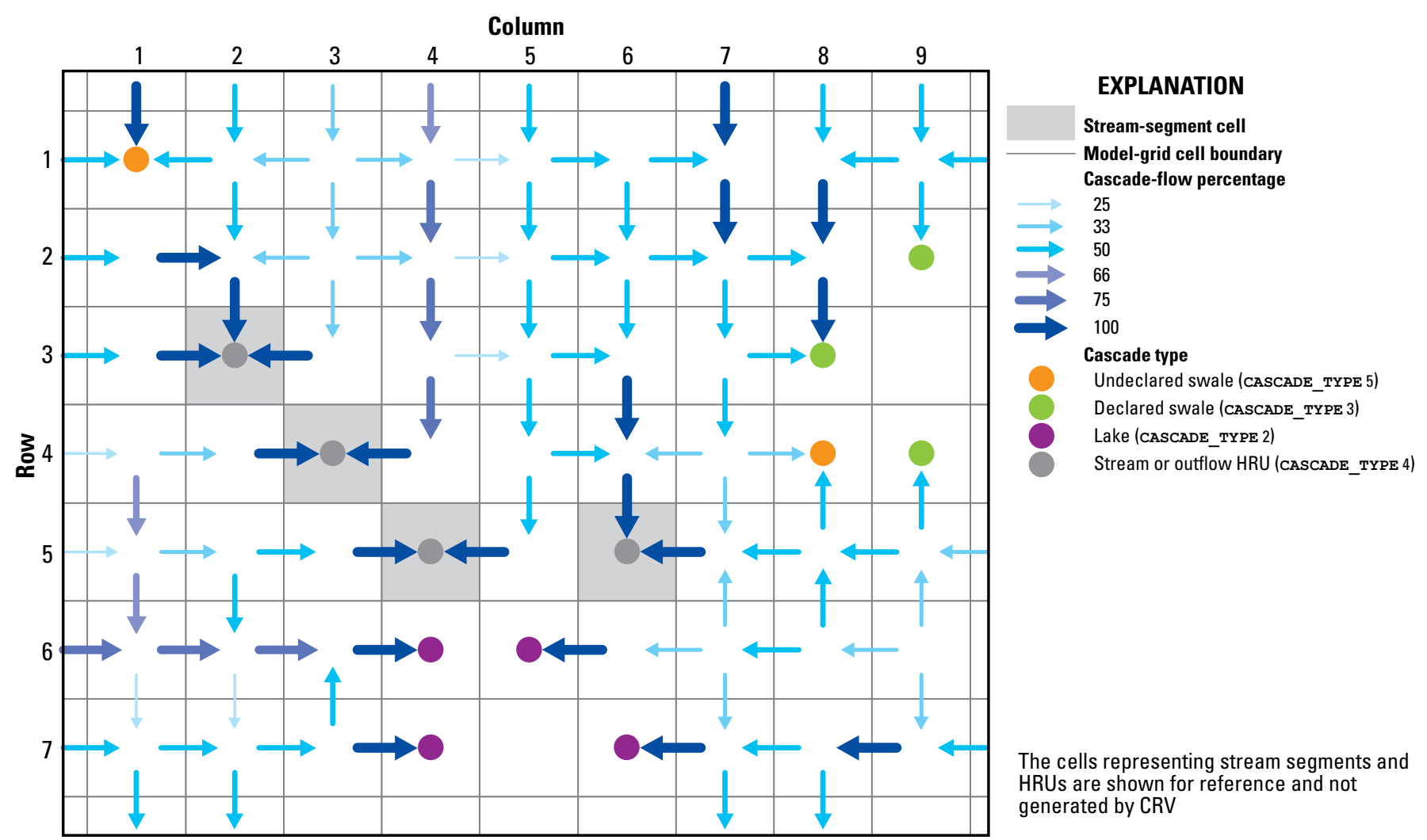

Figure 7. Diagram showing the cartographic representations applied by (Cascade Routing Visualization) CRV to hypothetical cascade link line features (Cascade flow percentage; cascade parameter CASC_PCT) and the cascade types (CASCADE_TYPE). 
2C). All of the files that are necessary to run the sample applications are available with the CRT download from the USGS Software webpage provided in the "Preface" of this report.

The input and output files for the sample applications are formatted to clearly indicate whether they are input or output files. Input-file names use upper-case text, and output-file names use lower-case text. While this formatting convention is not required for CRT input, it allows users to clearly distinguish input files from output files in the CRT directory. As previously described in the introduction, input and output file extensions indicate the end use of the file. Data files (.DAT extension) are used for CRT input. Text files (.txt file extension) are files created for reviewing CRT operation statistics, PRMS/GSFLOW cascade-dimension information, and CRV ArcGIS visualization data. Output files (.out file extension) are provided for evaluation of individual parameters generated by CRT. Parameter files (.param) are parameter files formatted for direct PRMS or GSFLOW input. While the file extensions can vary, any CRT file can be opened with any standard text editing software.

\section{Application 1: Sagehen Creek Basin, California}

\section{Description of the Basin}

Sagehen Creek Basin is a USGS Hydrologic Benchmark Network Basin on the east slope of the northern Sierra Nevada (fig. 8) northwest of Truckee, California, in the Tahoe National Forest. The watershed is a densely forested alpine basin of moderate size (27 square kilometers) that has a high relief ranging from 1,935 to 2,653 meters (m) in elevation and consists of a perennial stream network that includes Sagehen Creek (Burnett and Jennings, 1965; Rademacher and others, 2005; Markstrom and others, 2008).

\section{Application Overview}

The Sagehen Creek Basin applications illustrate (1) the use of CRT for computations of cascades for a simulation in which all of the stream reaches in the basin are used in the generation of cascades (application 1A), (2) the generation of PRMS-only groundwater cascades by using a steady-state groundwaterhead distribution to describe the groundwater potentiometric surface (application 1B), and (3) the use of CRT Fill Procedure to rectify undeclared swales or local depressions (applications $1 \mathrm{~A}$ and $1 \mathrm{~B})$.

\section{Input}

The Sagehen Creek Basin watershed boundary was delineated in GIS from a USGS $10 \mathrm{~m}$ DEM of the basin resampled to a $90 \mathrm{~m}$ DEM. The edges of the watershed are assumed to be no-flow boundaries across which there is no surface-water or groundwater flow, except where the stream crosses the boundary. The basin is represented in PRMS by a horizontal, rectangular grid of cells (HRUs) consisting of 79 columns by 71 rows. Each of the 5,609 HRUs is $90 \mathrm{~m}$ on each side, with 3,378 active HRUs. The perennial stream network was delineated into 17 stream segments and 189 stream reaches. In these applications, all stream reaches were used to generate cascades because the entire stream network within the basin is perennial and mostly gaining, and because groundwater recharge through the streambed is minimal. Therefore, the simulated stream reaches are discharge points at which surface and groundwater cascades calculated by CRT can terminate. 


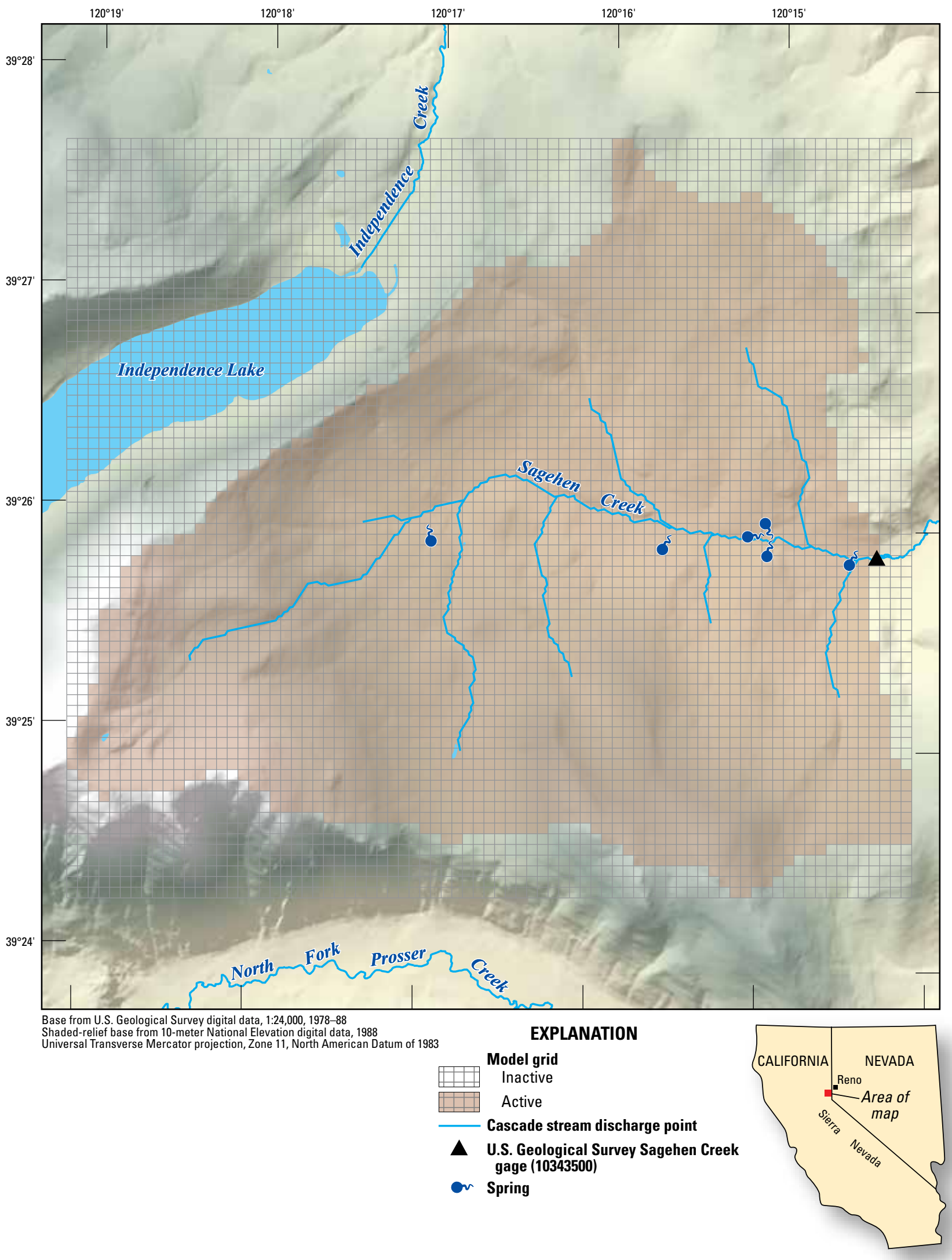

Figure 8. Sagehen Creek Basin PRMS model domain showing active model boundary; stream network; and springs. 
Input for Application 1A: All Streams With Fill Procedure

In this application, HRU_ID and CELI_ID are equivalent, so the parameter HRUFLG $=0$ (fig. 9). Because all stream reaches are considered in the computation of cascades, parameter STRMFLG is set to 1. Flow to downslope receiving HRUs is partitioned evenly among all receiving HRUs by setting FLOWFLG to 0 . After generating cascades, the cascades will be verified by using the CRV visualization toolbox; therefore, parameter VISFLG is set to 1 . Default CRT output (IPRN=1) was selected. The initial land-surface elevation model derived from the resampled DEM had many local depressions, thus highlighting the need for the CRT Fill Procedure during cascade computation. The CRT Fill Procedure was employed by setting parameter IFILL $=1$ on the first line of the HRU_CASC.DAT input file. The default values of 0.1 $\mathrm{m}$ for the parameter DPIT and 10,000 maximum iterations (OUTITMAX) were used. In this example, there were only inactive and active land HRUs (HRU TYPE 0 and 1, respectively). Streams and the outflow HRŪ were the only cascade discharge features in this sample application.

Because all stream reaches are included in the generation of cascades (that is, STRMFLG=1 in the HRU_CASC.DAT file), it is necessary to specify the total number of stream reaches in the model grid by use of parameter NREACH in the STREAM_CELLS.DAT file (fig. 10). Information describing the location of each stream reach follows in item 2 of the input file. The value of ON_OFF is specified as 1 for every stream reach, which indicates that each stream reach will be included in the generation of cascades.

In addition to HRU-stream cascade links, there is also a basin-outflow HRU. Specifying an outflow HRU is important because it indicates that the fill procedure will not be applied to this HRU. This outflow HRU, which is located at row 40 and column 76 in the model grid, is specified by use of the OUTFLOW_HRU.DAT input file. The outflow HRU is required to prevent the CRT fill procedure from failing; it specifies one active HRU that will not be filled.
Input for Application 1B: PRMS-Only Groundwater Cascades by Using Steady-State Potentiometric Surface

This application demonstrates how to use the steady-state groundwater-head distribution from a MODFLOW simulation to create groundwater cascades. The land-surface elevation model in the LAND_ELEV.DAT file is replaced with the steady-state groundwater head distribution derived from a steady-state MODFLOW simulation of the Sagehen Creek Basin. As with application 1A, this application uses the values of STRMFLG $=1$, IPRN $=1$, and FLOWFLG $=0$ in the HRU_CASC.DAT file. The DPIT parameter is set to a small value $(0.01)$ to reflect the potentially smaller differences in groundwater heads between HRUs, and OUTITMAX is set to 10,000 .

\section{Output}

CRT creates the file outputstat.txt that describes CRT operation, including input data, selected options, output that includes undeclared swales corrected during the CRT Fill Procedure, and information on how CRT computed cascades (fig. 11).

Figure 9. Line 1 from HRU_CASC.DAT input file for Sagehen Creek Basin application.

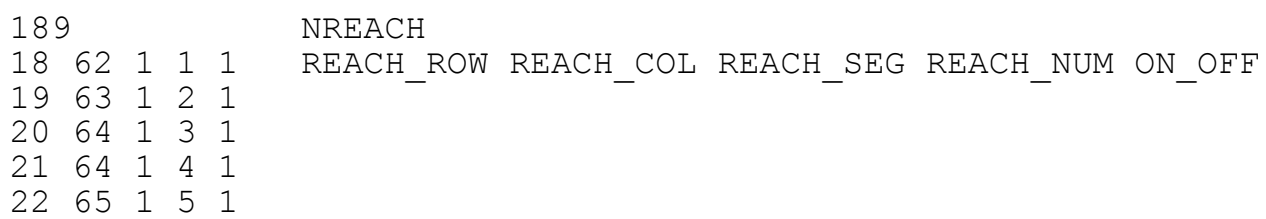

Figure 10. Lines 1-6 of the STREAM_CELLS.DAT input file for Sagehen Creek Basin application. 




Figure 11. Excerpt from outputstat.txt showing a summary of Cascade Routing Tool (CRT) options and filled hydrologic response units (HRUs) for the Sagehen Creek Basin application.

After resampling the $10 \mathrm{~m}$ DEM to a $90 \mathrm{~m}$ DEM in ArcGIS, local depressions (undeclared swales) were created as artifacts of the spatial averaging method used to resample the DEM (fig. 12A). Undeclared swales are undesirable if they are artifacts of the DEM-processing algorithms and do not represent real topographical features. The orange circles located in some HRUs (fig. 12B) illustrate the many local depressions remaining after the initial CRT evaluation. These local depressions resulted in generation of cascades that did not accurately represent flow in the model; these incorrect flow directions are shown by flow arrows on figure $12 B$ converging on the local depressions instead of continuing downslope toward the stream.

Figure $12 C$ shows the final cascade visualization for the same portion of the model domain as shown in figure $12 B$ after the CRT Fill Procedure was used to remove 24 local depressions (that is, the undeclared swales). The resulting cascades, shown on figure $12 C$, better represent flow paths within the system. Undeclared swales have been corrected, and flow lines converge downslope HRU-to-HRU toward the stream network. 


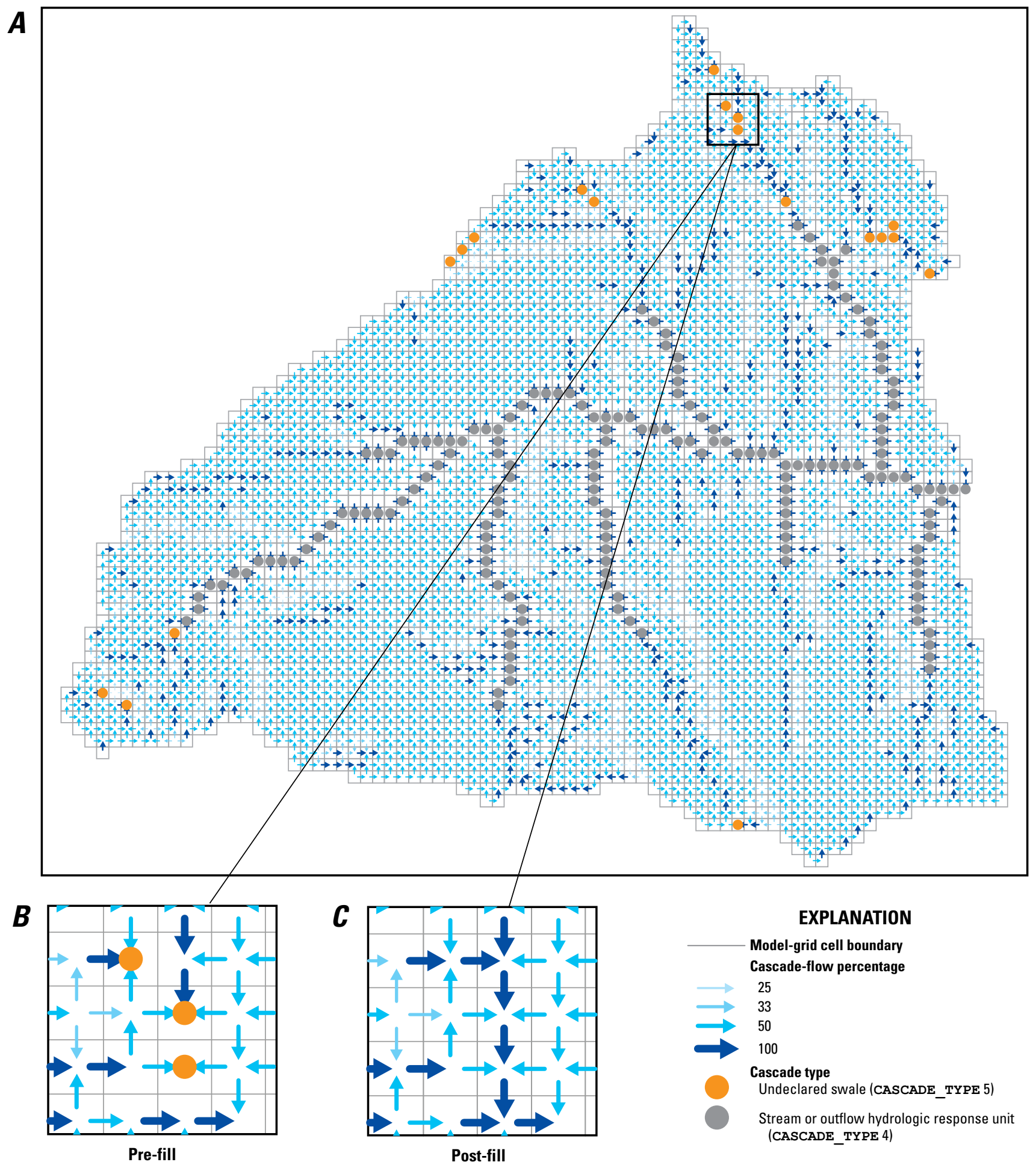

Figure 12. A, Depiction of Sagehen Creek Basin PRMS model domain showing stream network, cascade flow arrows, and undeclared swales. $\boldsymbol{B}$, Part of the model domain showing undeclared swales and cascade flow arrows before the land-surface model was corrected with Cascade Routing Tool (CRT) Fill Procedure. C, The same part of the model domain after elimination of the undeclared swales by use of the CRT Fill Procedure. 


\section{Application 2: Lower Walker River Basin, Nevada}

\section{Description of the Basin}

The Lower Walker River Basin (LWRB; fig. 13) is located in west-central Nevada. The LWRB is a closed basin, with ephemeral and perennial stream networks, and contains nonstream cascade discharge features Walker Lake, Webber Reservoir, and Double Springs playa. The climate of the LWRB is classified as mid-latitude semi-arid Great Basin desert (Houghton and others, 1975, page 3). Walker Lake (fig. 13) is a terminal lake within the basin. The main outflow from the lake is by evaporation. The Double Springs playa is located in the northeastern part of the model domain (fig. 13) and is a flat surface of clay with a thin salt crust. Surface runoff discharges to the playa and then evaporates.

The main source of inflow to the lake is streamflow from the Walker River. While Walker River is the biggest and most significant tributary to Walker Lake, there are other tributaries that occasionally contribute water to the lake. The only perennial stream reaches within the study area in addition to Walker River are a few in the Wassuk Range; however, except under exceptionally rare high-runoff conditions, these streams are dry prior to reaching Walker Lake. Walker Lake is the terminus of the Walker River and is the lowest point in the basin. The general direction of groundwater flow is toward Walker Lake, and groundwater generally discharges to the lake (Lopes and Allander, 2009).

\section{Application Overview}

The Lower Walker River Basin applications illustrate the use of CRT (1) to generate cascades to non-stream discharge points such as designated swales, lakes, and reservoir HRUs; (2) to rectify undeclared swales; (3) to partition flow among HRUs on the basis of differences in land-surface slope among HRUs (that is, option FLOWFLG=1); (4) to generate cascades for a PRMS-only simulation in which only selected stream reaches (and then no stream reaches) are used to generate steady-state recharge distributions that could be used for a MODFLOW or GSFLOW simulation; and (5) to generate groundwater cascades for PRMS-only simulations based on modified HRU CASCADE_TYPEs. These applications illustrate how a simulated stream network can be coded in the CRT input files to appropriately represent the groundwater-recharge processes within the PRMS simulation. Three applications are provided to illustrate different approaches for doing this: the generation of cascades without any stream reaches (application $2 \mathrm{~A})$, the generation of cascades with selected stream reaches (application 2B), the generation of PRMS-only groundwater cascades assuming the potentiometric surface mimics the land surface (application 2C).
Input

The LWRB hydrologic system is represented in the PRMS model by a horizontal, rectangular grid of HRU cells that consists of 178 columns and 317 rows. Each of the 56,426 HRUs is $400 \mathrm{~m}$ on a side. A filled $400 \mathrm{~m}$ DEM was developed from a resampled $10 \mathrm{~m}$ DEM of the basin and used to define the watershed and to generate a stream network. The landsurface elevation model used in the delineation of cascades is defined by the elevation at the centroid of each HRU; these data are shown in the LAND_ELEV.DAT input file. Although the default value for IPRN is equal to 1, condensed output $($ IPRN $=0)$ was selected to simplify display in an application with many HRUs. The parameter HRU_TYPE is set to a value of 2 for HRUs coincident with lake and reservoir HRUs. The outflow HRU location (OUTFLOW_ID) for the LWRB is the HRU that contains the lake desiccation point (fig. 13) in the HRU located at row 151 and column 89. The Double Springs playa is a swale feature that must be specified as a designated swale HRU when using the CRT Fill Procedure to rectify undeclared swales. Swale HRUs are designated by setting HRU_TYPE to a value of 3 for HRUs that intersect the swale feature. This was done for HRUs (designated swale) that are coincident with Double Springs playa in the HRU_CASC. DAT input file. This ensures that the swales will not be filled during the CRT Fill Procedure, and cascade links to these swales will be generated.

After resampling the LWRB DEM in ArcGIS and using the Arc DEM Fill tool, hundreds of local depressions (611 undeclared swales) were created as artifacts of the spatial averaging method used to resample the DEM. Cascades computed with these undeclared swales will not accurately represent flow in the model. Overland flow will not be routed out of that HRU. In a PRMS-only simulation, undeclared swales will only contribute flow to GWRs. In GSFLOW simulations, undeclared swales will only contribute flow to MODFLOW finite-difference groundwater cells. A complete listing of undeclared swale HRUs is provided in the outputstat.txt file for all CRT simulations. CRT Fill Procedure was used to remove undeclared swales in LWRB before cascades were generated by setting the value for IFILL=1 in the HRU_CASC.DAT input file.

\section{Input for Application 2A: Cascades Generated Without Stream Reaches}

This application demonstrates cascades generated without any stream network. This approach assumes that all streams in the model are either dry or generally losing and contribute to groundwater recharge. Figure 14 illustrates item 1 of the HRU_CASC.DAT input file used for this application and includes specification of parameter STRMFLG as 0 to generate cascades without any stream reaches; flow through the basin is represented as HRU-to-HRU cascade links. Stream reaches are not used in this example (STRMFLG $=0$ ), thus the STREAM_CELLS.DAT file is not required by CRT. Outflow 




Figure 13. Lower Walker River PRMS/GSFLOW model domain showing active model boundary; stream network; and non-stream cascade-discharge features Walker Lake, Webber Reservoir, and Double Springs Playa, Nevada. 
HRUs specified in the OUTFLOW_HRU.DAT are used to constrain the CRT fill procedure and define where flow exits the model domain; the lake desiccation point in this example. Relative slopes among cells are used to partition water from upslope HRUs to downslope receiving HRUs (FLOWFLG=1), input data for the visualization software (CRV) are written to file vis.txt (VISFLG $=1$ ), condensed output was selected (IPRN=0), CRT Fill Procedure was used (IFILL=1), and the suggested default values for DPIT $(0.1 \mathrm{~m})$ and OUTITMAX $(10,000)$ were used.

\section{Input for Application 2B: Cascades Generated With Selected Stream Reaches}

This application demonstrates how to represent spatially variable stream-reach recharge behavior for a PRMS-only simulation to compute steady-state groundwater recharge. Figure 15 shows item 1 of the HRU_CASC.DAT file for this application. In this application, only selected stream reaches are considered in the generation of cascades (STRMFLG=1), which assumes that selected reaches do not contribute significant recharge. Relative slopes among cells are used to partition water from upslope HRUs to downslope receiving HRUs (FLOWFLG $=1$ ), visualization data are written to file vis. txt (VISFLG=1), default output is selected (IPRN=1), CRT Fill Procedure is used (IFILL=1), and the suggested default values for DPIT $(0.1 \mathrm{~m})$ and OUTITMAX $(10,000)$ were used.

Recharge through streambeds within the LWRB has been shown to be spatially variable, with the highest recharge rates mainly along ephemeral and valley alluvial channels and the lowest recharge rates within the consolidated mountain bedrock. Because of this spatial variability of recharge within the stream network, it was necessary to identify those streams that could be contributing recharge and remove them during the generation of cascades. Part of the STREAM_CELLS.DAT input file for this application is shown on figure 16. In order to remove a stream reach during the generation of cascades, the ON_OFF parameter for that reach should be specified as 0 , which allows cascades as HRU-to-HRU cascade links at these locations instead. For example, the five stream segments identified in figure 16 were removed because they are thought to be locations of groundwater recharge; therefore, cascade paths should not end at the HRUs where the stream reaches are located and should continue instead as HRU-to-HRU cascade links until the downslope cascade link is an HRU with a cascade discharge feature such as an outflow HRU, stream reach, swale, lake, or reservoir. See the sections titled "Stream Networks and Lakes" and "PRMS Recharge Estimates" for more information on stream-reach selection for PRMS-only groundwater-recharge estimates.

\section{Input for Application 2C: PRMS-Only Groundwater Cascades Using Topography}

This application demonstrates how to generate groundwater cascades by using the same land-surface elevation data that were used in application 2A as a proxy for groundwater elevations. This method assumes that the potentiometric-surface topography is correlated to the land-surface topography. There were two modifications to the input files for application $2 \mathrm{~A}$ to create input files for application $2 \mathrm{C}$. The first modification was to change the designated swale HRUs coinciding with the Double Springs Playa from swale-type HRUs (HRU_TYPE=3) to land-type HRUs (HRU_TYPE=1). The second modification was to change lake type HRUs (HRU_TYPE=2) coinciding with Walker Lake and the Webber Reservoir to land-type HRUs (HRU_TYPE=1). These modifications were necessary because groundwater cascade links cannot terminate in a swale or lake for PRMS-only simulations. As with application 2A, this application uses the values of STRMFLG $=0, \mathbf{I P R N}=0$, and FLOWFLG $=1$.

Figure 14. Line 1 of HRU_CASC.DAT input file for the Lower Walker River Basin application 2A showing use of option STRMFLG=0.

Figure 15. Line 1 of the HRU_CASC.DAT input file for the Lower Walker River Basin application 2C showing use of option STRMFLG=1.

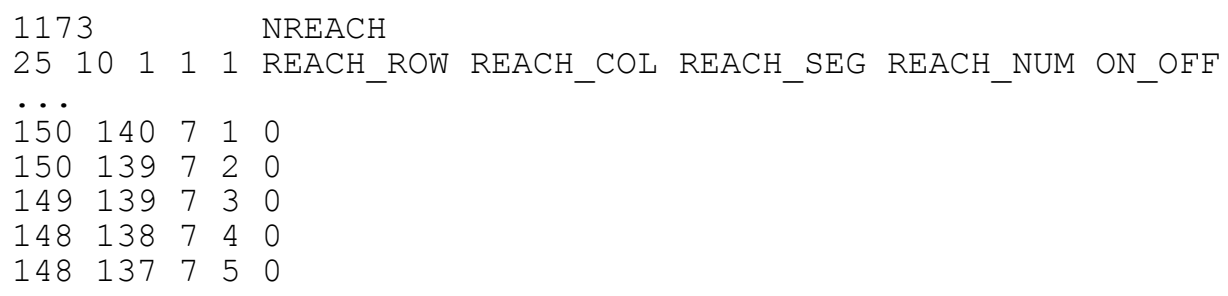

Figure 16. Lines 1-2 and 284-288 of the STREAM_CELLS.DAT input file for the Lower Walker River Basin application 2C showing use of option ON_OFF=0. 


\section{Output}

Figure 17 illustrates how cascades determined by CRT for the condition in which stream reaches are not included (application 2A, fig. 17, parts $A$ and $C$ ) differ from those determined for the condition in which selected stream reaches are included (application 2C, fig. 17, parts $B$ and $D$ ). In simulations with no streams, flow is routed HRU-to-HRU (or HRU-to-Lake), and all HRUs except those specified as lakes can contribute to groundwater recharge. In simulations in which selected stream reaches are included, cascade-flow arrows converge on the nearest HRU containing a stream reach (gray dots, fig. 17D) or lake (purple dots, fig. 17D) and flow is routed through the defined stream network. Groundwater recharge from streams is not calculated for HRUs containing stream reaches in a PRMS-only simulation.

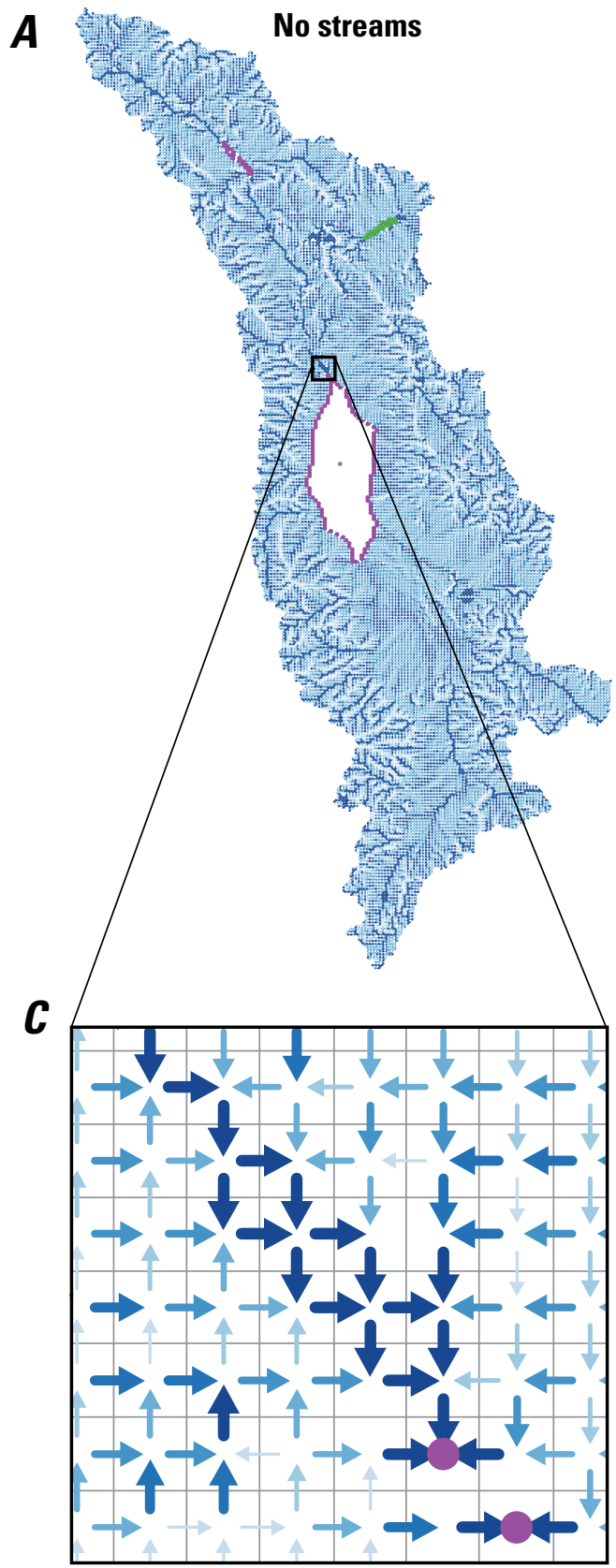

EXPLANATION


Figure 17. Depiction of Lower Walker River Basin PRMS and GSFLOW model domains showing stream network, lake boundaries, Double Springs Playa designated swale, cascade flow arrows, and undeclared swales: $\boldsymbol{A}$, model domain with no stream reaches, $\boldsymbol{B}$, model domain with selected stream reaches, $\boldsymbol{C}$, part of the model domain showing cascade flow arrows in the simulation with no stream reaches, and $\boldsymbol{D}$, part of the model domain showing cascade flow arrows in the simulation with selected streams. 


\section{Summary}

Cascades are pre-defined flow paths used for surface and subsurface water routing in hydrologic models. PRMS and GSFLOW include a cascading-flow procedure to route computed flows from upslope to downslope HRUs, GWRs, stream segments, lakes, reservoirs, and other watershed outflow HRUs. The cascading-flow procedure allows for routing flows between spatial units to account for the changes in hydrologic response, timing, and drainage patterns as water moves from upslope to downslope portions of a basin. Cascade parameters are read by PRMS and GSFLOW when the Cascade Module is made active. The Cascade Module provides a means of routing lateral flows among HRUs, which allows a more realistic representation of the effects of topography and topology on the drainage of a watershed. Cascades are important for simulating the occurrence of divergent and convergent flows that can result in reinfiltration of overland runoff and saturated excess runoff.

The Cascade Routing Tool (CRT) is a computer program that has been developed to compute flow paths between HRUs used to discretize a watershed for PRMS and GSFLOW models. CRT is used external to the models so that cascades can be evaluated prior to a PRMS or GSFLOW simulation to make sure that water is routed appropriately, while honoring the topography and flow paths through a hydrologic system. Several applications are presented in this document to illustrate how CRT input can be created to account for a variety of model configurations, including those with ephemeral and perennial stream networks, lakes, playas, and swales. Output from CRT provides important information about cascade computation and cascade-link error checking.

CRT includes an ArcGIS toolbox called Cascade Routing Visualization (CRV), which was developed to visualize cascades in ArcGIS. CRV can execute CRT from the ArcGIS environment or import an existing CRV visualization file. Visualization using CRV can help locate errors in CRT input, examine CRT cascade output, and help users decide which CRT configuration is best suited for their simulation.

\section{References Cited}

Burnett, J.L., and Jennings, C.W., 1965, Chico Quadrangle, scale 1:250,000: State of California, Division of Mines and Geology.

ESRI, 2011, Understanding representations: ArcGIS Desktop Help 10.0, accessed October 31, 2011, at http://help. arcgis.com/en/arcgisdesktop/10.0/help/index.html\#/ Understanding_representations/008t0000000r000000/.

Ford, L.R ., and Fulkerson, D.R., 1956, Maximal flow through a network: Canadian Journal of Mathematics, v. 8, no. 3, p. 399-404.
Garbrecht, Jurgen, and Martz, L.W., 1997, The assignment of drainage direction over flat surfaces in raster digital elevation models: Journal of Hydrology, v. 193, no. 1-4, p. $204-213$

Harbaugh, A.W., 2005, MODFLOW-2005, The U.S. Geological Survey modular ground-water model - the GroundWater Flow Process: U.S. Geological Survey Techniques and Methods 6-A16, variously paginated.

Houghton, J.G., Sakamoto, C.M., and Gifford, R.O., 1975, Nevada's weather and climate: Nevada Bureau of Mines and Geology Special Publication 2, 78 p.

Leavesley, G.H., Lichty, R.W., Troutman, B.M., and Saindon, L.G., 1983, Precipitation-runoff modeling system-User's manual: U.S. Geological Survey Water-Resources Investigations Report 83-4238, $207 \mathrm{p}$.

Lopes, T.J., and Allander, K.K., 2009, Hydrologic setting and conceptual hydrologic model of the Walker River basin, west-central Nevada: U.S. Geological Survey Scientific Investigations Report 2009-5155, 84 p

Markstrom, S.L., Niswonger, R.G., Regan, R.S., Prudic, D.E., and Barlow, P.M., 2008, GSFLOW-Coupled ground-water and surface-water flow model based on the integration of the Precipitation-Runoff Modeling System (PRMS) and the modular ground-water flow model (MODFLOW-2005): U.S. Geological Survey Techniques and Methods 6-D1, $240 \mathrm{p}$.

Niswonger, R. G. and Prudic, D.E., 2005, Documentation of the Streamflow-Routing (SFR2) Package to include unsaturated flow beneath streams a modification to SFR1, U.S. Geological Techniques and Methods Book 6, Chapter A13: 62 .

Pan, Feifei, Stieglitz, Marc, and McKane, R. B., 2012, An algorithm for treating flat areas and depressions in digital elevation models using linear interpolation: Water Resources Research, v. 48, W00L10, doi:10.1029/ 2011 WR010735.

Rademacher, L.K., Clark, J.F., Clow, D.W., and Hudson, G.B., 2005 , Old groundwater influence on stream hydrochemistry and catchment response times in a small Sierra Nevada catchment-Sagehen Creek, California: Water Resources Research, v. 41, no. W02004, doi:10.1029/2003WR002805, $10 \mathrm{p}$.

Tóth, J., 1963, A theoretical analysis of groundwater flow in small drainage basins: Journal of Geophysical Research, v. 68 , no. 16 , p. $4795-4812$. 


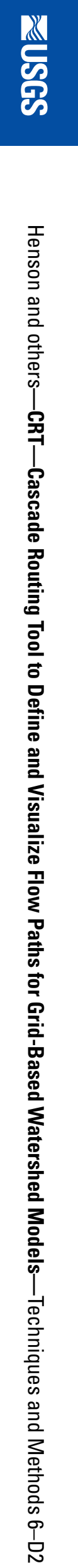